\title{
Commodity Price Volatility with Endogenous Natural Resources ${ }^{\text {ts }}$
}

\author{
James Hansen ${ }^{\mathrm{a}, *}$, Isaac Gross ${ }^{\mathrm{b}}$ \\ ${ }^{a}$ Department of Economics, University of Melbourne \\ ${ }^{b}$ Keble College, University of Oxford
}

\begin{abstract}
Natural resource reserves are exogenous in models of small commodity exporters. Changes in the stock of reserves play no role in the macroeconomy including in business cycle volatility, trade dynamics or exchange rate volatility. We consider richer supply dynamics and model exploration and depletion. We show that an endogenous supply of reserves is important for capturing the stylised facts associated with commodity price shocks including a commodity currency, the crowding-out of noncommodity activity (Dutch-Disease) and a volatile business cycle.

We also consider how exploration and depletion affect the ranking of optimal monetary and taxation policies. When natural resource reserves are held fixed, monetary policy is an efficient tool for stabilising the effects of commodity price shocks. However, when exploration and depletion are accounted for, using interest rates to stabilise the effects of commodity price changes becomes inefficient. Using taxes on the resource sector, specifically an ad valorem royalty, remains efficient. Keywords: Commodity currencies, commodity prices, Dutch Disease, non-renewable resources, optimal policy.

JEL Codes: E63, F41, Q33, Q38
\end{abstract}

\footnotetext{
${ }^{*}$ Corresponding author: James Hansen, 111 Barry Street, Level 4 FBE Building, University of Melbourne VIC 3010, Australia. Phone: +61 38344 2142, james.hansen@unimelb.edu.au. Isaac Gross: Keble College, Parks Road, Oxford, OX1 3PG, UK, isaac.gross@keble.ox.ac.uk.
} 


\section{Introduction}

Commodity prices are volatile. In recent decades prices for non-renewable resource commodities have more than doubled and then halved. ${ }^{1}$ Such volatility, although large, is not without precedent with several large price cycles over the past century (Figure 1; Jacks, 2013; Caputo and Chang, 2015). Over the past two decades, world commodity trade has increased more than sevenfold and export shares have been rising over time. ${ }^{2}$ The size of these price changes, together with the pattern of increasing export concentration, has renewed interest in the quantitative effects of commodity price changes. Two central questions are whether price volatility is beneficial or costly, and how economic policy should optimally respond. ${ }^{3}$

\section{Figure 1: Trends and Cycles in Real Commodity Prices Since 1900}
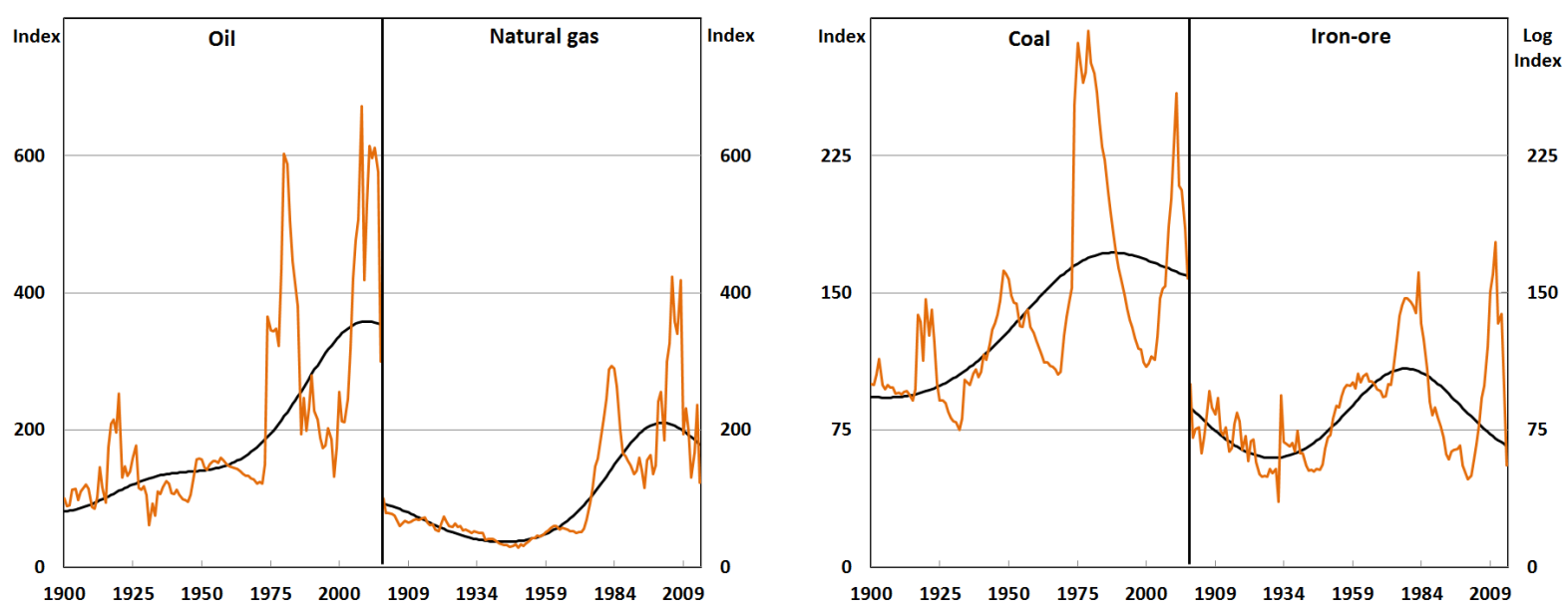

Notes: Data are from Jacks, D. (2013), "From Boom to Bust: A Typology of Real Commodity Prices in the Long Run", NBER Working Paper 18874. All indices have base period 1900=100.

A common assumption when answering these questions is that the stock of domestic resource reserves - deposits of minerals, oil or gas held in the ground - is known, exogenous and non-exhaustible. ${ }^{4}$ There is no process by which firms can augment ex-

\footnotetext{
${ }^{1}$ Typical examples of these commodities include oil, gas, iron-ore, coal and base metals such as aluminium, copper, lead, nickel and zinc.

${ }^{2}$ Measured between between 1995 and 2011 (UNCTADstat), as a share of total merchandise trade it more than doubled from 10 to 22 per cent. At the peak of the boom, commodity export revenues made up 67 per cent of total merchandise export revenue in Africa, 57 per cent in Oceania, 24 per cent in America and 20 per cent in Asia.

${ }^{3}$ Defining a commodity exporter as exporting at least 20 per cent of its merchandise exports in the form of non-renewables, about a fifth of the world's population resides in these economies (UNCTADstat, 1995 to 2014).

${ }^{4}$ There is extensive literature on the effects of commodity price shocks in small open economies.
} 
isting reserves through exploration. The depletion of existing reserves is also ignored. These two channels, emphasised in natural resources literature, ${ }^{5}$ are abstracted from by assuming a Cobb-Douglas extraction technology where reserves play the role of exogenous technical change. There is little that differentiates natural resources from other sectors of the economy.

We consider a richer model of supply by integrating exploration, depletion and reserve scarcity into an otherwise standard small commodity exporting economy (SCE). Unlike the treatment of reserves as fixed and invariant to commodity price changes (exogenous), the supply of reserves is modelled as an endogenous state variable. Firms can invest to find new reserves through exploration. They also account for the fact that extracting reserves results in their depletion. We examine whether these additional supply dynamics are important for modelling the transmission of commodity price shocks, and the implications for domestic welfare and for optimal policy rules.

We focus on exploration and depletion as these are likely to be important for capturing the propagation of commodity price shocks. They have been emphasised in partial equilibrium models of natural resources (Devarajan and Fisher, 1982; Cairns, 1990; Halvorsen and Layton, 2015), where the opportunity cost of depletion - the fact that resources extracted today are not available for future extraction - affects resource firms' optimal extraction decisions, while exploration defines the feasible set from which production can occur (Pindyck, 1978; Lasserre, 1985; Livernois and Uhler, 1987). Both are important for understanding how resource firms adjust to price changes.

Reserves may also be important from a macroeconomic perspective. With limited propagation of commodity price shocks when they are held fixed, standard models

Recent examples include: Bjørnland and Thorsrud (2016), who focus on productivity spillovers between the resource and non-resource sectors; Bodenstein et al. (2011), on oil price shocks and external adjustment; Natal (2012) on optimal monetary policy, and Jääskelä and Nimark (2011) who estimate a DSGE model for Australia. All of these examples assume that the supply of resources is exogenous, costless and inexhaustible.

Bems and de Carvalho Filho (2011) study precautionary saving and the current account allowing for an exhaustible supply (which is still exogenous and costless to extract); Dib (2008) and Benkhodja (2014) allow for costly extraction, but not exploration or depletion; Wills (2013) and Arezki et al. (2015) study the effects of exogenous reserve discoveries when viewed as news about future production. None of these studies consider reserves as an endogenous state variable that responds to price signals.

${ }^{5}$ See for example Hotelling (1931); Pindyck (1978); Heal (1993); Halvorsen and Layton (2015). 
have difficulty in explaining the correlation between commodity prices and macroeconomic volatility in SCEs (Bidarkota and Crucini, 2000; van der Ploeg, 2011; Berka, Crucini and Wang, 2012). Given the magnitude of adjustment that occurs through production quantities when commodity prices change, we investigate whether additional wealth effects associated with the discovery of new reserves can help to reconcile observations about commodity price volatility and macroeconomic performance.

There are several dimensions in which models with exogenous reserves are at odds with the data for SCEs. Perhaps most notable, is the implication that reserves growth is uncorrelated with price growth. Empirically, there is positive comovement in price growth, exploration activity and the subsequent discovery of new reserves. Firms have an increased incentive to look for new reserves when prices are high, and although not all exploration is successful, on average they find new deposits. Second, standard models imply significant positive comovement between price growth and extraction growth contemporaneously. In the data, the contemporaneous correlation is close to zero and the lagged correlation in growth is negative (prices first rise and by the time extraction increases price growth is already declining back to baseline). ${ }^{6}$ We show that exploration to find new reserves and the additional capital required to build new mines are important margins of adjustment that delay the extraction response and that this better explains the correlations observed in the data.

In terms of macroeconomic effects, models with exogenous reserves do not generate a "commodity currency" effect - an appreciation (depreciation) of the real exchange rate when commodity prices rise (fall). Simple regression analysis suggests the correlation between commodity prices and the real exchange rate is high at about 0.4 to 0.6 (Chen and Rogoff, 2003; Cashin et al., 2004). Similar findings are observed in Structural Vector Autoregressions (VARs) and Dynamic Factor Models. ${ }^{7}$ Standard models, where reserves are held fixed, predict a much lower correlation. ${ }^{8}$

Literature on the effects of commodity price volatility has also emphasised a

\footnotetext{
${ }^{6}$ See Berka et al. (2012) and Anderson et al. (2014).

${ }^{7}$ For SVAR evidence see Jääskelä and Smith (2013); for Dynamic Factor Model evidence see Charnavoki and Dolado (2014) and Bjørnland and Thorsrud (2016).

${ }^{8}$ For example, for Canada (Dib, 2008), Chile (Fornero et al., 2014), or in a standard calibrated model (Benkhodja, 2014), the peak response of the real exchange rate to a one percent positive shock to commodity prices is an appreciation of 0.05 to 0.10 per cent.
} 
"Dutch-Disease" effect - the crowding out of activity in non-commodity sectors in response to higher commodity prices, especially in non-commodity exports. Evidence of it has been found in panel studies - see, for example, Sachs and Warner (2001), Stijns (2003) and van der Ploeg (2011), and in structural time series models (Jääskelä and Smith, 2013; Charnavoki and Dolado, 2014; Bjørnland and Thorsrud, 2016). ${ }^{9}$ Notwithstanding, standard models do not produce a large reallocation of goods or labour across sectors. ${ }^{10}$ The maximal decline in non-commodity exports is about a 0.02 to 0.10 per cent (Dib, 2008; Benkhodja, 2014) and some models imply an absence of Dutch-Disease altogether (Fornero et al., 2014).

Incorporating exploration and depletion better captures the transmission of commodity price changes. A model where reserves respond to changes in price can produce positive comovement between price growth and exploration growth, and between exploration growth and reserves growth. It also produces a weak contemporaneous correlation between price and extraction growth and a negative correlation with a lag, as well as a significant appreciation of the real exchange rate and large movements of goods and labour across sectors. Exploration that leads to the discovery of new reserves and that permanently increase the production possibilities set is central to these results.

Firms increase exploration when commodity prices rise and any new reserves found result in a permanent increase the feasible production set - that is, new reserves found never depreciate. This generates additional complementarity in extraction, exploration, investment and mining labour demand - facilitating a greater expansion of the resource sector when commodities price rise and a larger contraction when prices fall. ${ }^{11}$ Assuming constant returns to scale in production and an absence of pricing

\footnotetext{
${ }^{9}$ Norway is an interesting exception. Bjørnland and Thorsrud (2016) find significant productivity spillovers offset the presence of Dutch-Disease in Norway.

${ }^{10} \mathrm{We}$ are restricting attention to dynamic stochastic general equilibrium models. Models without expectations or optimising behaviour have generated significant Dutch-Disease (Corden and Neary, 1982; Corden, 2012).

${ }^{11} \mathrm{~A}$ useful (albeit imperfect) analogy is to think of a standard firm with Cobb-Douglas technology and access to research and development that can permanently increase productivity. With a higher price for its product, the firm can discover new ideas that permanently increase output and productivity, generating larger effects on production and factor usage when prices rise than in the case in which R\&D cannot be accessed. Exploration works in much the same way, though the analogy is not perfect because depletion will to some extent attenuate the mechanism.
} 
power in world markets, reserves are an endogenous stochastic trend - transitory changes in price have permanent effects on the stock of reserves and on the broader economy. ${ }^{12}$ Indeed, endogenous reserves magnifies the effects of commodity price changes on both the resource and non-resource sectors. The implied commodity currency and sectoral reallocation effects are similar to those in the classical theory of Dutch-Disease in "two or three-speed economies" (Corden and Neary, 1982; Corden, 2012).

We compare a standard exogenous reserves model with an endogenous counterpart that has exploration and depletion. Parameterising the models to a prototypical SCE (Australia), we first study how commodity price volatility affects household welfare: is price volatility beneficial or is it costly? In the model with exogenous reserves, welfare is not sensitive to price volatility. Households are willing to forgo only a small share of their steady state consumption, less than 0.01 per cent, to be insulated from a small increase in price volatility (an increase in the standard deviation of price of 1 per cent). ${ }^{13}$ When reserves are endogenous the gloomy story has more traction: households are significantly more adverse to commodity price volatility and willing to forgo as much as 2.65 per cent of their steady state consumption to avoid the same increase in price volatility.

We next consider the ranking of optimal monetary and taxation policy. ${ }^{14}$ With exogenous reserves, optimal interest rate and resource taxation rules are close substitutes and can eliminate the effects of commodity price volatility on welfare. In relative terms, we find that monetary policy - implemented through an optimised interest rate rule - is preferred either to a tax on resource sector profits or revenue. This supports the emphasis on optimal monetary policy in response to commodity price shocks in previous literature (Frankel, 2003; Cãto and Chang, 2013; Hevia and Nicolini, 2013; Bergholt, 2014).

When reserves are endogenous, however, the rankings change. An optimal in-

\footnotetext{
${ }^{12}$ Aguiar and Gopinath (2007) and Chen and Crucini (2016) have previously noted the importance of permanent shocks for explaining business cycle volatility in small open economies.

${ }^{13}$ This is true even in the presence of significant asset market frictions that prevent households from insuring against commodity price shocks.

${ }^{14}$ The optimality of alternative taxation structures has been investigated in partial equilibrium models in Gamponia and Mendelsohn (1985), Deacon (1993), Daniel et al. (2010) and Boadway and Keen (2015).
} 
terest rate rule can no longer eliminate the effects of price volatility on welfare and is an inefficient tool for stabilising price shocks. The reason is that with greater spillover of commodity price shocks onto the non-resource sector, changes in interest rates induce greater volatility in domestic non-mining production (hereafter domestic production), non-resource exports and consumption. In effect, a "blunt instrument" critique applies where it is not optimal to change interest rates to reduce volatility in the resource sector as this will only amplify volatility in the rest of the economy.

In contrast, optimal taxation rules, specific to the resource sector and that condition on price, remain efficient. For example, an optimally set revenue tax (ad valorem royalty) mitigates changes in resource firm revenues. It reformulates commodity price shocks as lump-sum perturbations to households' budget constraints. With lower consumption volatility and less intersectoral flows of goods and labour, welfare is higher. Taxes on resource rents or reserves can yield similar welfare gains, though these policies are less efficient.

The next section provides stylised observations on reserves and commodity prices. Section 3 discusses two small open economies with natural resources, one with exploration and depletion and one where reserves are held fixed. Section 4 presents our quantitative results and studies optimal policy. The final section concludes.

\section{Stylised Observations}

We begin with summary evidence on the ability of the standard and endogenous reserve models to explain the data. ${ }^{15}$ Table 1 , columns two to four, provides summary correlations for three prototypical SCE's - Australia, Canada and Norway. It highlights three patterns: (a) there is positive comovement between commodity price growth and exploration growth, and subsequently reserves growth; ${ }^{16}$ (b) extraction growth is contemporaneously uncorrelated with price growth and negatively correlated at lags; ${ }^{17}$ and (c) investment and price growth are positively correlated both

\footnotetext{
${ }^{15}$ These correlations are not model targets when we parameterise the models (as discussed below).

${ }^{16}$ The latter being consistent with a delay between exploration, discovery and then classification of new reserves.

${ }^{17}$ This pattern is also found for a panel of 66 countries in Berka et al. (2012) with an average contemporaneous correlation between price growth and commodity production of -0.08 , which compares with the average for Australia, Canada and Norway of -0.03 .
} 
contemporaneously and with a lag. Similar patterns using micro data for oil have been documented by Anderson et al. (2014).

Table 1: Summary Correlations

\begin{tabular}{|c|c|c|c|c|c|}
\hline$\tau$ & Australia & Canada & Norway & Exogenous & Endogenous \\
\hline \multicolumn{6}{|c|}{ Exploration Growth $(t)$ and Reserves Growth $(\tau)$} \\
\hline t & -0.04 & -0.08 & -0.25 & 0.00 & 0.09 \\
\hline $\mathrm{t}+1$ & -0.08 & -0.19 & -0.11 & 0.00 & 0.21 \\
\hline $\mathrm{t}+2$ & 0.36 & 0.22 & 0.58 & 0.00 & 0.29 \\
\hline \multicolumn{6}{|c|}{ Price $(t)$ and Exploration $(\tau)$} \\
\hline $\mathrm{t}$ & 0.22 & 0.40 & 0.16 & $\mathrm{~N} / \mathrm{A}$ & 0.52 \\
\hline$t+1$ & 0.32 & -0.02 & 0.49 & $\mathrm{~N} / \mathrm{A}$ & 0.19 \\
\hline$t+2$ & 0.45 & -0.25 & 0.37 & $\mathrm{~N} / \mathrm{A}$ & 0.14 \\
\hline \multicolumn{6}{|c|}{ Price $(t)$ and Extraction $(\tau)$} \\
\hline $\mathrm{t}$ & 0.01 & 0.06 & -0.16 & 0.71 & 0.14 \\
\hline$t+1$ & -0.55 & -0.32 & -0.33 & 0.01 & -0.04 \\
\hline$t+2$ & -0.18 & -0.35 & -0.32 & 0.05 & 0.01 \\
\hline \multicolumn{6}{|c|}{ Price $(t)$ and Investment $(\tau)$} \\
\hline t & 0.23 & 0.59 & -0.18 & 0.56 & 0.38 \\
\hline $\mathrm{t}+1$ & 0.42 & 0.11 & 0.23 & 0.48 & 0.36 \\
\hline $\mathrm{t}+2$ & 0.31 & -0.20 & 0.30 & 0.38 & 0.31 \\
\hline $\begin{array}{l}\text { Notes } \\
\text { (Austr } \\
\text { explord }\end{array}$ & orrelations & lated on & $\begin{array}{l}01 \text {; for } \\
\text { refer } t\end{array}$ & $\begin{array}{l}\text { periods cover } \\
\text { ), with the exc } \\
\text { scription of th } \\
\text { tions based on }\end{array}$ & $\begin{array}{l}\text { are } 19^{7 r} \text { to } 20 \\
\text { ion of Norwegic } \\
\text { mpirical data, s } \\
\text { nulated data fro }\end{array}$ \\
\hline
\end{tabular}

The standard model is only consistent with the third fact (Table 1, column five). With exogenous reserves there is no correlation between price and exploration growth or exploration and reserves growth. The standard model also predicts a strong positive correlation between extraction and price growth, whereas the data suggest little contemporaneous correlation and a negative correlation with a lag. The model with endogenous reserves can produce positive comovement in price, exploration and reserves growth, and little comovement between extraction growth and price growth contemporaneously, as well as a negative correlation with a lag (Table 1, column six). It also remains consistent with the third stylised fact, producing a positive correlation in investment and price growth.

Using the same data for Australia and Canada, similar patterns can be observed 
in a panel-VAR in price, exploration and reserves. ${ }^{18}$ Identifying a price shock by assuming that commodity prices are contemporaneously uncorrelated with shocks to exploration and reserves, a one standard deviation increase in price leads to significant increases in exploration expenditure and subsequently reserves (Figure 2). The persistence of the reserves response to a transitory price rise is a key feature of the data that an endogenous reserves model can reproduce, while the exogenous model assumes the response is zero in all periods. The next section discusses the models for endogenous and exogenous reserves in detail and their parameterisation.

\section{Figure 2: Comovement in Price, Exploration and Reserves}

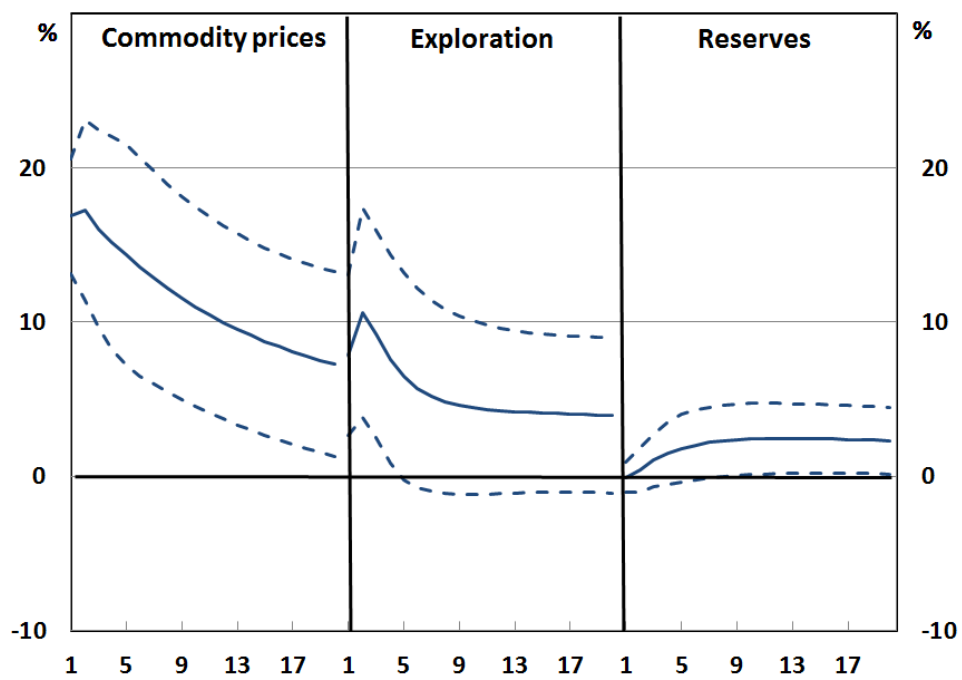

Notes: Based on a Panel-VAR that uses annual data on economically demonstrable reserves, commodity prices and exploration from 1976 to 2010 for Australia and Canada. The shock is a one standard deviation increase in commodity prices; 95 per cent confidence intervals are reported.

\section{The Theoretical Models}

We assume that there are four sectors: resources; non-tradeables; imports; and non-resource exports. Resources are modelled as non-renewable and non-exhaustible with costly extraction. This sector is perfectly competitive with capital drawn from abroad and labour from the domestic economy, a pattern that is common in many SCEs. ${ }^{19}$ When reserves are modelled as endogenous, firms have access to a costly

\footnotetext{
${ }^{18}$ Norway time series on exploration are only available over a short time frame (see Table 1 notes).

${ }^{19}$ The assumption of importing mining specific capital from abroad is consistent with the stylised fact that a large fraction of the capital installed in mining projects is imported. For example, recent
} 
exploration technology that is a convex function of the level of exploration undertaken and the economy-wide (aggregate) stock of natural resource reserves. Firms also account for the fact that extraction depletes the existing stock of reserves. When reserves are exogenous, there is neither exploration nor depletion and reserves are assumed constant over time.

For the rest of the economy, we consider an environment similar to that in Adolfson et al. (2007), though only the minimal set of frictions - those required to match the dynamics of a commodity price shock - are used. The three remaining sectors - nontradeables, imports and exports - are each populated by a continuum of firms of unit measure that are monopolistically competitive and subject to sector-specific Calvo pricing rigidities. Prices in all sectors are set in local currency terms. Households make consumption and labour supply decisions optimally, but face nominal wage rigidity when choosing their optimal wage. Financial markets are incomplete with an endogenous risk premium on foreign borrowing and partial domestic ownership of the resource sector. The economy is closed through an optimal interest rate rule. In subsequent discussion, we will additionally consider optimal taxation rules.

\section{Domestic Households}

We assume a continuum of identical households of unit measure with perfect consumption insurance within the period. Focusing on a representative household, preferences are additively separable with constant relative risk aversion, an external habit over consumption and a constant elasticity of substitution between the supply of resource and non-resource labour:

$$
U\left(C_{t}, H_{t}^{n}, H_{t}^{r}\right)=\frac{\left(\frac{C_{t}}{V_{t}}\right)^{1-\xi_{c}}}{1-\xi_{c}}-\varsigma\left(\frac{H_{t}^{n^{\frac{1}{\gamma_{h}}}}}{H^{n}}+\frac{H_{t}^{\frac{1}{\gamma_{h}}}}{H^{r}}\right)^{\xi_{h} \gamma_{h}}
$$

$C_{t}$ is an aggregate consumption bundle (containing non-traded and imported goods), $V_{t}=\int_{0}^{1} C_{t-1}(j) d j$ is the external habit, $H_{t}^{n}$ and $H_{t}^{r}$ are the sector-specific supplies of labour to the non-resource and resource sectors $\left(H^{n}\right.$ and $H^{r}$ denote the corresponding

large-scale floating platforms used to extract liquid natural gas in Australia have been entirely produced and assembled abroad. For broader evidence on the imported content of capital, see Connolly and Orsmond (2011). 
steady state values), $\xi_{c}$ is the coefficient of relative risk aversion over consumption relative to the habit, $\xi_{h}$ governs disutility over aggregate labour supply and $\gamma_{h}$ governs the elasticity of substitution between resource and non-resource labour supply. ${ }^{20}$

Households can trade in two risk-free bonds - a domestic bond, $B_{t}$, and a foreign bond, $B_{t}^{*}$. To decouple the real exchange rate from the ratio of foreign to domestic marginal utilities of consumption and allow for incomplete sharing of commodity price risk, we follow Benigno and Thoenissen (2008) and assume that financial markets are incomplete: when domestic residents issue claims in foreign currency they must pay a premium on this borrowing, $\Phi_{t}$. As we note below, this premium will be important for generating a "commodity currency" when reserves are endogenous. The flow budget constraint for households is:

$$
\begin{aligned}
P_{t}^{c} C_{t}+\frac{B_{t}}{\left(1+i_{t}\right)}+\frac{S_{t} B_{t}^{*}}{\left(1+i_{t}^{*}\right) \Phi_{t}} & =W_{t}^{n} H_{t}^{n}+W_{t}^{r} H_{t}^{r}+B_{t-1}+S_{t} B_{t-1}^{*} \\
& +\nu \Psi_{t}^{r}+\Psi_{t}^{n}+\Psi_{t}^{o}+\Psi_{t}^{x}-T_{t}
\end{aligned}
$$

where $\Psi_{t}^{r}, \Psi_{t}^{n}, \Psi_{t}^{o}, \Psi_{t}^{x}$ are the aggregate profits (dividends) paid to households from the resource, non-traded, import and non-resource export sectors, $P_{t}^{c}$ is the price of the aggregate consumption bundle, $T_{t}$ is a lump-sum tax (or subsidy), ${ }^{21} W_{t}^{n}$ and $W_{t}^{r}$ are the nominal wages paid for supplying non-resource and resource labour, and $i_{t}$ and $i_{t}^{*}$ are the domestic and foreign interest rates. The Euler equations are:

$$
\begin{aligned}
& \Theta_{t}=\beta E_{t}\left(\left(1+i_{t}\right) \frac{P_{t}^{c}}{P_{t+1}^{c}} \Theta_{t+1}\right) \\
& \Theta_{t}=\beta E_{t}\left(\left(1+i_{t}^{*}\right) \Phi_{t} \frac{P_{t}^{c}}{P_{t+1}^{c}} \Theta_{t+1} \frac{S_{t+1}}{S_{t}}\right)
\end{aligned}
$$

where the marginal utility of consumption is $\Theta_{t} \equiv \frac{1}{C_{t}}\left(\frac{C_{t}}{V_{t}}\right)^{1-\xi_{c}}$.

We assume a constant elasticity of substitution between non-traded and imported goods $\left(\eta_{c}\right)$ and allow for home-bias in consumption $(\alpha) .{ }^{22}$ The foreign debt risk-

\footnotetext{
${ }^{20}$ The external habit (Abel, 1990) is useful as the level of consumption will be non-stationary in equilibrium.

${ }^{21}$ In the subsequent discussion on optimal taxation rules, this will be the mechanism through which taxes are remitted to households (Section 5.1).

${ }^{22}$ See Equations (D.15) to (D.17) in the online Appendix.
} 
premium is a function of the domestic economy's debt deflated by its stock of reserves:

$$
\ln \Phi_{t} \equiv-\varphi_{b}\left(\frac{S_{t}}{P_{t}^{c}} \frac{B_{t}^{*}}{R_{t}}-\frac{S}{P^{c}} \frac{B^{*}}{R}\right)
$$

implying that international lenders take into account both the stock of debt held and the capacity to repay it, as captured by the stock of domestic reserves, when choosing to lend. ${ }^{23}$ Optimal labour supply choices and wage setting are discussed in further detail below.

\subsection{The Resource Sector}

The resource sector with exploration and depletion draws from previous work by Pindyck (1978), Heal (1993), Sweeney (1993), Bohn and Deacon (2000) and Halvorsen and Layton (2015). We assume many competitive resource producers that maximise profit taking commodity prices as given. They choose extraction, $X_{t}$, investment in physical capital, $I_{t}$, labour inputs, $H_{t}^{r}$, expenditure on exploration, $D_{t}$, and have value function:

$$
V\left(K_{t}, R_{t}\right)=\max _{\left\{X_{t}, I_{t}, H_{t}^{r}, D_{t}\right\}}\left\{\begin{array}{c}
S_{t} P_{t}^{r^{*}} X_{t}-W_{t}^{r} H_{t}^{r}-S_{t} P_{t}^{*} I_{t}-C\left(D_{t}, \widetilde{R}_{t}\right) \\
+\beta E_{t}\left(M_{t+1} V\left(K_{t+1}, R_{t+1}\right)\right)
\end{array}\right\}
$$

with constraints:

$$
\begin{aligned}
X_{t} & =\left(H_{t}^{r} A_{t}^{r}\right)^{\eta} K_{t}^{\gamma} R_{t}^{1-\eta-\gamma} \\
K_{t+1} & =(1-\delta) K_{t}+\left(1-\Xi\left(\frac{I_{t}}{I_{t-1}}\right)\right) I_{t} \\
R_{t+1} & =R_{t}+\omega_{t+1} D_{t}-X_{t}
\end{aligned}
$$

where $K_{t}$ (physical capital) and $R_{t}$ (firm-level reserves) are firm-specific state variables; and $\widetilde{R}_{t}$ (aggregate reserves), $W_{t}^{r}$ (wages), $P_{t}^{r^{*}}$ (commodity prices), $P_{t}^{*}$ (the price at which capital goods are imported), and $S_{t}$ (the nominal exchange rate) are aggregate state variables. ${ }^{24} \beta$ is the rate of time preference and $M_{t+1}$ is its stochastic

\footnotetext{
${ }^{23}$ In effect, reserves are a pledgable asset when the domestic economy borrows. This is reasonable given the foreign specificity in capital required to build new mines and the high foreign ownership share in resources.

${ }^{24}$ Asterisks are used to denote variables measured in foreign currency terms. Aggregate reserves is the sum of reserves across all domestic resource firms in the economy, $\widetilde{R}_{t}=\int_{0}^{1} R_{t}(i) d i$.
} 
component reflecting the ownership structure of resource firms. For exploration costs, we assume:

$$
C\left(D_{t}, \widetilde{R}_{t}\right)=P_{t}^{n} \frac{Q^{r}}{\phi_{m c}}\left(e^{\phi_{m c}\left(\frac{D_{t}}{\widetilde{R}_{t}}-\frac{D}{\widetilde{R}}\right)}-(1-\Omega)\right) \widetilde{R}_{t}
$$

where $\widetilde{R}$ and $D$ are the steady state aggregate levels of reserves and exploration, $\phi_{m c}$ governs the sensitivity of costs to exploration activity, and $\Omega$ measures steady state (fixed) exploration costs.

Exploration costs are an increasing convex function of firm-level exploration and the stock of aggregate reserves. We assume the cost function is homogenous of degree one so that the profit function is homogenous of degree one, with constant returns to scale in mining production, and that marginal costs are positive and increasing in the amount of firm-level exploration $\left(\frac{\partial C}{\partial D_{t}}>0, \frac{\partial^{2} C}{\partial D_{t}^{2}}>0\right) .{ }^{25}$ The latter assumption captures the idea that larger deposits are often more costly to find and that exploration costs rise as firms drill further underground or in less accessible locations. ${ }^{26}$ Marginal costs that are positive and increasing in the aggregate stock of reserves $\left(\frac{\partial C}{\partial \widetilde{R}_{t}}>0\right.$, $\left.\frac{\partial^{2} C}{\partial \widetilde{R}_{t}^{2}}>0\right)$ captures increasing scarcity when looking for new deposits after existing deposits have been found. ${ }^{27}$

Importantly, we abstract from a known finite bound on new reserves. This is useful because the policy functions that solve the resource firms' program are time invariant and can be integrated within a broad class of small open economy models. The theoretical rationale is that, given a sufficiently high price, firms will always have an incentive to look for new reserves and, at least to some extent, will be able to find them even if it becomes more costly to do so. Increasingly scarce, though nonexhaustible reserves, have been previously emphasised by Pindyck (1978), Devarajan

\footnotetext{
${ }^{25}$ These assumptions are common in natural resources literature (Heal, 1993; Bohn and Deacon, 2000).

${ }^{26}$ Recent research has focused on more granular production structures such as stocks of heterogenous quality and different types of reserves, but we abstract from that level of detail.

${ }^{27}$ Although new reserves can be discovered in perpetuity, it becomes increasingly costly to find them as the stock of existing reserves increases. Our approach is motivated by previous literature, which assumes that resources are non-exhaustible but that exploration costs are increasing in the cumulative sum of past exploration flows (for example Lasserre (1985); Livernois and Uhler (1987)). We use the stock of reserves rather than the cumulative total of past exploration as this allows for delineation effects - the fact that drilling and extracting existing reserves reduces the cost of finding new linked deposits.
} 
and Fisher (1982), Lasserre (1985) and Livernois and Uhler (1987) amongst others. ${ }^{28}$ Empirically, this approach has provided a reasonable approximation as reserves have either grown or remained stationary over time in many SCEs rather than being in trend decline. ${ }^{29}$

The extraction process and the law of motion for capital, Equations (6) and (7), are standard. The former is Cobb-Douglas and allows for exogenous labour-augmenting technical change $\left(A_{t}^{r}\right)$. Investment adjustment costs are included to capture the fact that building new mines or expanding existing capital is costly and takes time. Reserves are an endogenous state variable that can be increased through exploration and depleted via extraction, Equation (8). Uncertainty over exploration is captured by the random variable $\omega_{t+1}$, which is assumed i.i.d. with normalised mean $E_{t}\left(\omega_{t+1}\right)=1$. The following necessary conditions hold in equilibrium:

$$
\begin{aligned}
S_{t} P_{t}^{r^{*}} & =(1+\zeta) \frac{W_{t}^{r}}{A_{t}^{r}} X_{t}^{\zeta} K_{t}^{-\mu} R_{t}^{\mu-\zeta}+Q_{t}^{r} \\
S_{t} P_{t}^{*} & =Q_{t}^{k}\left(1-\Xi\left(\varrho_{t}\right)-\Xi^{\prime}\left(\varrho_{t}\right) \varrho_{t}\right)+\beta E_{t}\left(M_{t+1 \mid t} Q_{t+1}^{k} \Xi^{\prime}\left(\varrho_{t+1}\right) \varrho_{t+1}^{2}\right) \\
\frac{\partial C\left(D_{t}, R_{t}\right)}{\partial D_{t}} & =Q_{t}^{r}
\end{aligned}
$$

where $\varrho_{t} \equiv \frac{I_{t}}{I_{t-1}}$.

Equation (10) equates the marginal revenue of extraction with the marginal cost of extraction, where the latter includes both the cost of extraction in period $t$ and the opportunity cost that reserves extracted today cannot be extracted in the future. Equation (11) equates the marginal cost of importing capital to its marginal return, accounting for the presence of investment-adjustment costs. ${ }^{30}$ Equation (12) implies that firms explore to the point where marginal cost is equal to the expected present discounted value of an extra unit of reserves. The marginal values of reserves and

\footnotetext{
${ }^{28}$ It is also common in natural resources to allow for a non-exhaustible backstop even if a given resource may have finite supply (van der Ploeg and Withagen, 2012).

${ }^{29}$ It is an alternative approach to that of a finite bound, where firms understand what reserves are available and simply extract them at an optimal rate without the need for exploration - the standard Hotelling model. For the sample over which we estimate, the non-exhaustible though scarce discoveries approach is a better description of the data - production and reserves have grown over time instead of reserves (exploration) declining as predicted by the case of a finite bound with a large (small) initial reserve stock (Pindyck, 1978).

${ }^{30}$ For investment adjustment costs, a standard quadratic function is used with $\Xi^{\prime}(1)=0, \Xi^{\prime \prime}(1)=$ $\kappa$.
} 
capital are given by:

$$
\begin{aligned}
& Q_{t}^{r}=\beta E_{t}\left(M_{t+1 \mid t}(\zeta-\mu) \frac{W_{t+1}^{r}}{A_{t+1}^{r}} X_{t+1}^{1+\zeta} K_{t+1}^{-\mu} R_{t+1}^{\mu-\zeta-1}+M_{t+1 \mid t} Q_{t+1}^{r}\right) \\
& Q_{t}^{k}=\beta E_{t}\left(M_{t+1 \mid t} \mu \frac{W_{t+1}^{r}}{A_{t+1}^{r}} X_{t+1}^{1+\zeta} K_{t+1}^{-\mu-1} R_{t+1}^{\mu-\zeta}+M_{t+1 \mid t} Q_{t+1}^{k}(1-\delta)\right)
\end{aligned}
$$

Resource firms are owned by both domestic and foreign households, and use the real stochastic discount factor:

$$
M_{t+1 \mid t}=\left(\nu \frac{\Theta_{t+1}}{\Theta_{t}}+1-\nu\right) \frac{P_{t}^{c}}{P_{t+1}^{c}}
$$

where $\nu$ is a reduced-form parameter capturing the domestic ownership share and $\Theta_{t}$ is the marginal utility of domestic households in period $t$. If $\nu=1$, the model is consistent with domestic households having full ownership. In the case that $\nu=0$, resource firms maximise their real domestic currency value, but take no account of domestic households preferences - a zero domestic ownership share. ${ }^{31}$

To capture spillovers from resource sector activity to domestic production (Bishop and Rayner, 2013; Bergholt, 2014), we assume exploration activity also requires nontraded goods as an input with a fixed-proportions technology: $Y_{t}^{r, n}=D_{t} \frac{Q^{r}}{\phi_{m c}}$, where $Q^{r}$ is the steady state shadow price of one unit of reserves, $\phi_{m c}$ governs the sensitivity of exploration costs and $Y_{t}^{r, n}$ is the demand for non-traded inputs. ${ }^{32}$ This assumption will be important for obtaining a "three-speed" economy (Corden, 2012), one where the resources sector expands in response to positive commodity price shocks and there is crowding out of non-resource export activity, but the effects on non-traded production can be positive or negative depending on the relative size of spillovers across sectors (Bjørnland and Thorsrud, 2016).

In the economy where reserves are exogenous, Equation (8), is replaced with $R_{t}=R$ and Equation (12) is replaced with $D_{t}=0$. The two economies are otherwise identical.

\footnotetext{
${ }^{31}$ Similar assumptions are used in Favilukis et al. (2014) and Fornero et al. (2014). A theoretical motivation for this approach can be found in Sanford J. Grossman (1979) and Carceles-Poveda and Coen-Pirani (2010).

${ }^{32}$ Note that for a given percentage change in exploration activity, the same change will occur in demand for non-traded inputs. Similar results are obtained if we alternatively assume that domestic labour is required to install mining-specific capital or extraction directly employs non-traded inputs.
} 


\section{Non-mining Production}

Each non-traded producer, indexed by $i$, has access to production technology $Y_{t}^{s, n}(i)=\frac{A_{t}^{n}}{\chi_{t}} H_{t}^{n}(i)$ where $A_{t}^{n}$ is a common technology shock, $H_{t}^{n}(i)$ is an aggregate index of non-traded labour used by firm $i$, and $\chi_{t}$ is a common cost-push shock. Nontraded firms are monopolistically competitive and face a downward sloping demand function $\left(\frac{\bar{P}_{t_{0}}^{n}(i)}{P_{t}^{n}}\right)^{-\theta_{n}} Y_{t}^{d, n}$ where $\bar{P}_{t_{0}}^{n}(i)$ is the profit-maximising price chosen by firm $i, P_{t}^{n} \equiv\left(\int_{0}^{1} P_{t_{0}}^{n}(i)^{1-\theta_{n}} d i\right)^{\frac{1}{1-\theta_{n}}}$ is the shadow price of an extra bundle of non-traded goods and $\theta_{n}$ the elasticity of substitution between them. Non-traded producers face a Cavlo pricing rigidity when choosing their optimal price, as discussed below.

\section{Importers}

Importing firms purchase a final output bundle from the foreign sector and use this to produce a differentiated consumption import. We assume that the foreign supply of goods is perfectly elastic at a given world price $P_{t}^{*}$. Thus, real marginal costs, common to all importers, are $M C_{t}^{o}=S_{t} P_{t}^{*}$. Like non-tradeable producers, importers are also monopolistically competitive and face a Calvo friction when resetting their domestic currency price.

\section{Non-Commodity Exporters}

A non-commodity exporter, indexed by $j$, purchases a bundle of non-traded inputs from domestic producers and transforms this into a differentiated export good. The demand for inputs from non-traded producer $i$ by exporter $j$ is given by $Y_{t}^{n, x}(i, j)=$ $\left(\frac{P_{t}^{n}(i)}{P_{t}^{n}}\right)^{-\theta_{n}} C_{t}^{x}(j)$, where $C_{t}^{x}(j)$ is the demand for exporter $j$ 's output. The demand function for exports of type $j$ is:

$$
C_{t}^{x}(j)=\left(\frac{P_{t}^{x^{*}}(j)}{P_{t}^{x^{*}}}\right)^{-\theta_{x}} C_{t}^{*}
$$

where $C_{t}^{*}=\left(\frac{P_{t}^{x^{*}}}{P_{t}^{*}}\right)^{-\theta_{*}} Y_{t}^{*}$ is a measure of common demand for non-resource exports, $Y_{t}^{*}$ is foreign output, $P_{t}^{x^{*}}(j)$ is the price of export type $j$ in foreign currency terms, $P_{t}^{x^{*}}$ is an index of non-resource export prices in foreign currency terms, and $P_{t}^{*}$ is the foreign price index. As with Adolfson et al. (2007), these assumptions allow for competition amongst firms within the exporting sector and with the rest of the world. 
Exporters are monopolistically competitive, set their prices in foreign currency terms, and are also subject to Calvo pricing.

\section{Price Setting}

Non-traded goods producers, importers and exports all face independent sectorspecific Calvo pricing rigidities when setting prices. Focusing on non-traded producers, for the fraction $\left(1-\phi_{n}\right)$ of firms able to set their price optimally, they solve:

$$
\max _{\bar{P}_{t_{0}}^{n}(i)} E_{t_{0}} \sum_{t=t_{0}}^{\infty}\left(\phi_{n} \beta\right)^{t-t_{0}} \frac{P_{t_{0}}^{c} \Theta_{t}}{P_{t}^{c} \Theta_{t_{0}}}\left(\bar{P}_{t_{0}}^{n}(i)-M C_{t}^{n}\right)\left(\frac{\bar{P}_{t_{0}}^{n}(i)}{P_{t}^{n}}\right)^{-\theta_{n}} Y_{t}^{d, n}
$$

where $M C_{t}^{n} \equiv \frac{W_{t}^{n}}{A_{t}^{n}} \chi_{t}$ is the marginal cost of production for a domestic non-traded producer and $Y_{t}^{d, n}$ is a measure of aggregate non-traded demand. A recursive formulation of the optimal price is given by:

$$
\begin{aligned}
\bar{P}_{t}^{n} & =\left(\frac{\theta_{n}}{\theta_{n}-1}\right) \frac{V_{t}^{n}}{U_{t}^{n}} \\
V_{t}^{n} & =Y_{t}^{d, n} \Theta_{t} \frac{\left(P_{t}^{n}\right)^{\theta_{n}}}{P_{t}^{c}} \frac{W_{t}^{n}}{A_{t}^{n}} \chi_{t}+\beta \phi_{n} E_{t}\left(V_{t+1}^{n}\right) \\
U_{t}^{n} & =Y_{t}^{d, n} \Theta_{t} \frac{\left(P_{t}^{n}\right)^{\theta_{n}}}{P_{t}^{c}}+\beta \phi_{n} E_{t}\left(U_{t+1}^{n}\right)
\end{aligned}
$$

For the remaining fraction $\left(\phi_{n}\right)$ of firms not able to choose their price, they simply retain their price from the previous period. The shadow price of an extra unit of non-traded goods and non-traded profit are given by:

$$
\begin{aligned}
P_{t}^{n} & =\left(\left(1-\phi_{n}\right)\left(\bar{P}_{t}^{n}\right)^{1-\theta_{n}}+\phi_{n} P_{t-1}^{n^{1-\theta_{n}}}\right)^{\frac{1}{1-\theta_{n}}} \\
\int_{0}^{1} \Psi_{i t}^{n} d i & =P_{t}^{n} Y_{t}^{d, n}-\left(1-\tau_{n}\right) W_{t}^{n} H_{t}^{n}
\end{aligned}
$$

Similar Calvo pricing structures apply to importers and non-commodity exporters, who set prices in local currency terms. ${ }^{33}$

\footnotetext{
${ }^{33}$ See Equations D.23 to D.34 in the online Appendix.
} 


\section{Wage Setting and the Labour Market}

To allow for nominal wage rigidity in the non-traded sector, we assume that each household supplies specialised labour type $h$ that is imperfectly substitutable. Following Erceg et al. (2000), we assume an employment agency that combines this specialised labour using a Dixit-Stiglitz aggregator in the same proportions that firms would choose. The agency minimises the cost of producing the aggregate labour input, taking each household wage $W_{t}^{n}(h)$ as given, which it then sells back to the non-traded sector at aggregate wage $W_{t}^{n}=\left[\int_{0}^{1} W_{t}^{n}(h)^{\frac{1}{1-\theta_{w}}} d h\right]^{\frac{1}{1-\theta_{w}}}$. The aggregate demand for household of labour type $h$ is:

$$
H_{t}^{n}(h)=\left(\frac{W_{t}^{n}(h)}{W_{t}^{n}}\right)^{-\theta_{w}} H_{t}^{n}
$$

where $\theta_{w}$ governs labour substitutability within the non-traded sector. Being monopolistic suppliers, each household chooses their own nominal wage but are again subject to a Calvo restriction - only a random fraction of households are able to reset their wage in each period. For those able to choose their wage, the optimal contract is:

$$
\begin{aligned}
\bar{W}_{t}^{n} & =-\lambda_{w} \frac{U_{t}^{H}}{V_{t}^{H}} \\
V_{t}^{H} & =H_{t}^{n} \Theta_{t}+\beta \phi_{w} E_{t}\left(V_{t+1}^{H}\right) \\
U_{t}^{H} & =H_{t}^{n} \frac{\partial U\left(C_{t}, H_{t}^{n}, H_{t}^{r}\right)}{\partial H_{t}^{n}}+\beta \phi_{w} E_{t}\left(U_{t+1}^{H}\right)
\end{aligned}
$$

where $\Theta_{t}$ and $\frac{\partial U\left(C_{t}, H_{t}^{n}, H_{t}^{r}\right)}{\partial H_{t}^{n}}$ are the marginal utility (dis-utility) of consumption (nonresource labour) respectively, $\lambda_{w}=\varepsilon_{w} /\left(\varepsilon_{w}-1\right)$ is the non-resource wage markup and the probability of resetting the nominal wage is $1-\phi_{w}$. For households unable to re-optimise their wage they simply retain their wage from the previous period.

While there is nominal wage rigidity in the non-traded sector, there is less evidence of such rigidity in sectors subject to a high degree of international competition such as resources. ${ }^{34}$ For this reason, we simply assume perfectly competitive resource labour

\footnotetext{
${ }^{34}$ Our results are not sensitive to assuming a similar degree of nominal wage rigidity in the resources sector, or alternatively assuming that both labour markets are competitive and wages perfectly flexible.
} 
supply and that resource sector wages are flexible. ${ }^{35}$

\section{Monetary Policy}

Monetary policy follows a Taylor rule and targets inflation with gradual interest rate adjustment:

$$
\ln \left(1+i_{t}\right)=\left(1-\rho_{i}\right) \ln (1+\bar{i})+\left(1-\rho_{i}\right) \rho_{\pi} \ln \left(\frac{P_{t}^{c}}{P_{t-1}^{c}}\right)+\rho_{i} \ln \left(1+i_{t-1}\right)
$$

\section{Market Clearing}

All markets, real and financial, clear. Supply equals demand for each non-traded good $i\left(Y_{t}^{s, n}(i)=Y_{t}^{d, n}(i)\right)$. Aggregating across the continuum of goods, it follows that:

$$
\frac{A_{t}^{n} H_{t}^{n}}{\chi_{t}}=\left(\frac{\widetilde{P}_{t}^{n}}{P_{t}^{n}}\right)^{-\theta_{n}} Y_{t}^{d, n}
$$

Demand for non-traded goods arises from consumption, and as inputs in non-resource exports and exploration, $Y_{t}^{d, n}=\int_{0}^{1} C_{t}^{n}(h) d h+\int_{0}^{1} C_{t}^{x}(j) d j+\int_{0}^{1} Y_{t}^{r, n}(i) d i$ where $\widetilde{P}_{t}^{n}=\left[\int_{0}^{1} P_{t}^{n}(i)^{-\theta_{n}} d i\right]^{-\frac{1}{\theta_{n}}}$. Note that world demands for resource and non-resource exports are assumed perfectly elastic given prices $P_{t}^{r^{*}}$ and $P_{t}^{x^{*}}$, while the supply of imported goods and capital are also perfectly elastic given $P_{t}^{*}$.

\section{Exogenous Processes and the Rest of the World}

Table 2 summarises the exogenous processes in the endogenous and exogenous reserve models. As discussed further below, long-run cointegration restrictions are imposed on resource sector and non-traded productivity to ensure the model has a stationary representation. For cost push shocks, we assume an AR(1) process but allow them to be correlated with commodity price shocks. This is a reduced-form assumption to account for the positive correlation between commodity prices and production costs (Sims, 1992; Rotemberg and Woodford, 1996; Hamilton, 2003). ${ }^{36}$ For the rest of the world, we assume prices and quantities are consistent with a reduced-form VAR:

\footnotetext{
${ }^{35}$ That is, the nominal resource sector wage is simply $W_{t}^{r}=-\frac{\partial U\left(C_{t}, H_{t}^{n}, H_{t}^{r}\right)}{\partial H_{t}^{n}} / \frac{\partial U\left(C_{t}, H_{t}^{n}, H_{t}^{r}\right)}{\partial C_{t}}$.

${ }^{36}$ We assume $\chi_{t}$ follows a similar autoregressive process as that modelled for commodity prices: $\ln \chi_{t}=\rho_{r} \ln \chi_{t-1}+\Upsilon \varepsilon_{t}^{r^{*}}$ where $\Upsilon$ governs the elasticity of marginal costs with respect to commodity prices.
} 


$$
\mathbf{y}_{t}^{*}=\sum_{j=0}^{p} \mathbf{A}_{j} \mathbf{y}_{t-j}^{*}+\varepsilon_{t}
$$

where $\mathbf{y}_{t}^{*}=\left[\begin{array}{cccc}Y_{t}^{*} & i_{t}^{*} & P_{t}^{*} & P_{t}^{r^{*}}\end{array}\right]^{\prime}$ is a vector collecting all foreign prices and quantities and $\varepsilon_{t}$ is a $4 \times 1$ vector of reduced-form shocks including the shock that we focus on, commodity prices $\left(\varepsilon_{t}^{r^{*}}\right)$.

\section{Table 2: Exogenous Processes}

\begin{tabular}{llc}
\hline Description & Parametric Restrictions & Shock \\
\hline Resource sector productivity & Cointegrated with non-traded productivity & $\varepsilon_{t}^{A^{r}}$ \\
Non-traded productivity & Cointegrated with resource productivity & $\varepsilon_{t}^{A^{n}}$ \\
Exploration uncertainty & $E_{t}\left(\omega_{t+1}\right)=1$ & $\omega_{t+1}$ \\
Non-traded marginal costs & $\operatorname{AR}(1)$, correlated with commodity prices & $\chi_{t}$ \\
Commodity prices & $\operatorname{VAR}(1)$ & $\varepsilon_{t}^{r^{*}}$ \\
Foreign output & $\operatorname{VAR}(1)$ & $\varepsilon_{t}^{y^{*}}$ \\
Foreign price level & $\operatorname{VAR}(1)$ & $\varepsilon_{t}^{p^{*}}$ \\
Foreign interest rate & $\operatorname{VAR}(1)$ & $\varepsilon_{t}^{i^{*}}$ \\
\hline
\end{tabular}

\section{A Stationary Representation and Technology}

Assuming constant returns to scale in the extraction technology, the solution to the above system, and in particular for reserves, is non-stationary. This arises from the assumption that reserves never depreciate, that the resulting value function of resource producers is homogenous of degree one and that domestic production (nonresources and non-resources) is assumed to be small in world markets. ${ }^{37}$ This means that transitory shocks to commodity prices can propagate with permanent effects onto the resource sector and the rest of the economy. ${ }^{38}$ This result has an established precedent in empirical work used to identify the effects of commodity price shocks (Hamilton, 1983; Kilian, 2008; Jääskelä and Smith, 2013; Alquist and Coibion, 2014) and will be a key source of amplification in the model.

To find a stationary representation of the economy, we require two further assumptions: (i) that technology in the non-traded and resource sectors share a common stochastic trend with reserves; and (ii) that world export demand and reserves

\footnotetext{
${ }^{37}$ For further discussion on how general this property is, see Hansen and Gross (2013).

${ }^{38}$ Formally, even if the underlying commodity price shock has a transitory effect on price $\lim _{j \rightarrow \infty} E_{t}\left(\frac{\partial P_{t+j}^{r^{*}}}{\partial \epsilon_{t}^{r *}}\right)=0$, it can still have permanent effects on real variables - for example, $\lim _{j \rightarrow \infty} E_{t}\left(\frac{\partial R_{t+j}}{\partial \epsilon_{t}^{r *}}\right) \neq 0$ and $\lim _{j \rightarrow \infty} E_{t}\left(\frac{\partial X_{t+j}}{\partial \epsilon_{t}^{r *}}\right) \neq 0$.
} 
share the same trend. These assumptions ensure that sector shares are stationary and that the economy admits a balanced growth path (see the online Appendix for further discussion).

\section{Parameterising the Models}

Table 3 reports the list of endogenous variables in the two economies. A mixture of calibration and estimation is used to parameterise the models. Parameters that determine steady state or long run relationships are calibrated either in line with previous empirical literature or to match data on average production or factor input shares. Parameters that govern dynamics, and that do not affect the steady state, are estimated.

Table 3: List of Endogenous Variables

\begin{tabular}{clll}
\hline Variable & Description & Variable & Description \\
\hline$d_{t} \equiv \frac{D_{t}}{R_{t}}$ & New discoveries & $\frac{\bar{P}_{t}^{x^{*}}}{P_{t}^{x^{*}}}$ & Optimal export price \\
$y_{t}^{r, n} \equiv \frac{Y_{t}^{r, n}}{R_{t}}$ & Exploration inputs & $\frac{P_{t}^{n}}{P_{t}^{n}}$ & Optimal non-traded price \\
$C\left(D_{t}, \widetilde{R}_{t}\right)$ & Costs of exploration & $\frac{P_{t}^{o}}{P_{t}^{o}}$ & Optimal import price \\
$x_{t} \equiv \frac{X_{t}}{R_{t}}$ & Resource extraction & $\pi_{t}^{n} \equiv \frac{P_{t}^{n}}{P_{t}^{n-1}}$ & Non-traded inflation \\
$r_{t} \equiv \frac{R_{t}}{R_{t-1}}$ & Growth rate of reserves & $\pi_{t}^{*} \equiv \frac{P_{t}^{*}}{P_{t-1}^{*}}$ & Foreign inflation \\
$H_{t}^{r}$ & Resource labour & $\pi_{t}^{o} \equiv \frac{P_{t}^{o}}{P_{t-1}^{o}}$ & Import price inflation \\
$k_{t} \equiv \frac{K_{t}}{R_{t}}$ & Resource capital & $\pi_{t}^{c} \equiv \frac{P_{t}^{c}}{P_{t-1}^{c}}$ & Consumer price inflation \\
$i_{t}^{r} \equiv \frac{I_{t}}{R_{t}}$ & Resource investment & $i_{t}$ & Domestic interest rate \\
$c_{t}^{*} \equiv \frac{C_{t}^{*}}{R_{t}}$ & Foreign demand & $s_{t} \equiv \frac{S_{t}}{P_{t}^{c}}$ & Real exchange rate \\
$c_{t}^{x} \equiv \frac{C_{t}^{x}}{R_{t}}$ & Non-resource exports & $\Phi_{t}$ & Risk premium \\
$y_{t}^{n} \equiv \frac{Y_{t}^{n}}{R_{t}}$ & Non-mining production & $b_{t}^{*}=\frac{S_{t} B_{t}^{*}}{P_{t}^{c} R_{t}}$ & Real foreign debt \\
$H_{t}^{n}$ & Non-traded labour & $\psi_{t}^{r} \equiv \frac{\Psi_{t}^{r}}{P_{t}^{c} R_{t}}$ & Real resource profit \\
$c_{t} \equiv \frac{C_{t}}{R_{t}}$ & Consumption & $\psi_{t}^{n} \equiv \frac{\Psi_{t}^{n}}{P_{t}^{c} R_{t}}$ & Real non-traded profit \\
$c_{t}^{o} \equiv \frac{C_{t}^{o}}{R_{t}}$ & Consumption of imports & $\psi_{t}^{x} \equiv \frac{\Psi_{t}^{x}}{P_{t}^{c} R_{t}}$ & Real export profit \\
$c_{t}^{n} \equiv \frac{C_{t}^{n}}{R_{t}}$ & Non-traded consumption & $\psi_{t}^{o} \equiv \frac{\Psi_{t}^{o}}{P_{t}^{c} R_{t}}$ & Real import profit \\
$w_{t}^{r} \equiv \frac{W_{t}^{r}}{P_{t}^{c}}$ & Real wages (resources) & $M_{t \mid t+1}$ & Stochastic discount factor \\
$w_{t}^{n} \equiv \frac{W_{t}^{n}}{P_{t}^{c}}$ & Real wages (non-tradeables) & $\Theta_{t}$ & Household marginal utility \\
\hline
\end{tabular}




\subsection{Calibration}

The models are calibrated to a prototypical SCE, Australia, at an annual frequency. ${ }^{39}$ Parameters specific to the resource sector are reported in the upper panel of Table 4. The discount factor and depreciation rate are chosen in accord with existing literature. ${ }^{40}$ The exponents on capital and labour in the extraction technology $(\gamma$ and $\eta$ ), are chosen to match a steady state rate of annual extraction of two per cent, and a wage bill relative to total revenue of 11 per cent. ${ }^{41}$ The steady state value of exploration costs $(\Omega)$ is calibrated so that firms earn zero profits on average.

Table 4: Calibration

\begin{tabular}{|c|c|c|c|}
\hline Description & \multicolumn{2}{|c|}{ Calibration } & Reference \\
\hline \multicolumn{4}{|c|}{ Resource Sector } \\
\hline Labour factor exponent & $\eta$ & 0.13 & Steady state extraction \\
\hline Capital factor exponent & $\gamma$ & 0.49 & and labour share \\
\hline Depreciation rate & $\delta$ & 0.10 & Rees et al. (2015) \\
\hline Steady state exploration costs & $\Omega$ & 0.008 & Zero profits \\
\hline \multicolumn{4}{|c|}{ Rest of the Domestic Economy } \\
\hline Risk aversion & $\xi_{c}$ & 1.01 & Logarithmic preferences \\
\hline Household discount factor & $\beta$ & 0.96 & Average real interest rate \\
\hline Labour convexity & $\xi_{h}$ & 4 & Quadratic disutility from \\
\hline Labour substitution (across sectors) & $\gamma_{h}$ & 0.5 & aggregate labour supply \\
\hline Non-resource labour markup & $\lambda_{w}$ & 1.01 & Competitive labour supply \\
\hline Import share & $\alpha$ & 0.2 & Average import share \\
\hline Substitution elasticity (consumption) & $\eta_{c}$ & 1.01 & Rees et al. (2015) \\
\hline Substitution elasticity (non-traded) & $\theta_{n}$ & 7 & Jääskelä and Nimark (2011) \\
\hline Substitution elasticity (imports) & $\theta_{o}$ & 7 & Jääskelä and Nimark (2011) \\
\hline Substitution elasticity (exports) & $\theta_{x}$ & 7 & Jääskelä and Nimark (2011) \\
\hline Substitution elasticity (world) & $\theta_{*}$ & 0.10 & Rees et al. (2015) \\
\hline Calvo parameter (non-traded goods) & $\phi_{n}$ & 0.12 & Rees et al. (2015) \\
\hline Calvo parameter (imports) & $\phi_{o}$ & 0.03 & Rees et al. (2015) \\
\hline Calvo parameter (exports) & $\phi_{x}$ & 0.02 & Rees et al. (2015) \\
\hline Calvo parameter (wages) & $\phi_{w}$ & 0.33 & Bishop (2016) \\
\hline Domestic ownership share & $\nu$ & 0.35 & Connolly and Orsmond (201. \\
\hline Cost push parameter & $\Upsilon$ & 0.33 & Gerard (2012) \\
\hline
\end{tabular}

For the rest of the domestic economy, we use a calibration in line with Jääskelä

\footnotetext{
${ }^{39}$ This is the highest frequency with which detailed reserves data are available. Our results are robust to alternatively using Canadian or Norwegian data (online Appendix E).

${ }^{40}$ See for example Charnavoki (2010) and Garcia and Gonzalez (2010).

${ }^{41}$ The two percent average annual extraction rate reflects the average extraction rate in Australia's main resource commodities (online Appendix A). The wage bill share is consistent with Topp et al. (2008).
} 
and Nimark (2011) and Rees et al. (2015), who estimate medium-scale DSGE models for Australia. The domestic economy parameters are displayed in the lower panel of Table 4. We use identical elasticities of substitution within the non-traded goods, importing and non-resource export sectors, each consistent with a mark-up of 17 per cent. For the price stickiness parameters, we use the estimates provided in Rees et al. (2015) and Benedict et al. (2016), where the latter highlight that sectors with a larger share of non-traded costs are likely to have more stable prices than sectors who are exposed to a high degree of international competition. For non-resource sector wage stickiness, Bishop (2016) reports that around 24 per cent of jobs experience a wage change each quarter based on unit record data for Australia from 2000 to 2016. This equates to an annual wage rigidity coefficient of one third.

The degree of home bias in consumption matches an approximately 20 per cent import share in steady state, and the elasticity of substitution between consumption of non-traded goods and imports is set to one. The elasticity of substitution between resource and non-resource labour supply is also one, and the overall disutility from working is set at four - labour is relatively substitutable across sectors, but households are averse to increasing their total supply of labour. Although we allow for wage rigidity, we assume that labour supply within the non-traded sector is highly substitutable with an implied wage markup of 1 per cent. Together, these assumptions imply Frisch elasticities of about 0.35 in the non-traded sector and 0.88 in the resource sector. The degree of risk aversion is set at just above one, consumption preferences are close to logarithmic.

For the domestic ownership share of resource firms, this is calibrated to 0.35 and is above the estimate of one fifth in Connolly and Orsmond (2011). We use a higher share to account for the fact that not all cross-firm holdings of resource equities are declared and that nominee holding companies are used. ${ }^{42}$ Using a lower domestic ownership share only strengthens the findings we report below. For the correlation between cost-push and commodity price shocks, we calibrate this correlation to 0.33

\footnotetext{
${ }^{42}$ In Australia, domestic cross-firm holdings need need not be disclosed when they are less than 5 per cent of total equity (Connolly and Orsmond, 2011).
} 
consistent with evidence from VARs. ${ }^{43}$

For the cointegrating relationships that govern technology and world demand, we set the speed of adjustment to any change in reserves to be very low $(\vartheta=0.99)$, and the parameter governing short-run dynamics $(\widetilde{\vartheta})$ to one. This implies that mining technology, non-mining technology and world demand are almost entirely insensitive to changes in domestic reserves in the short run, but slowly converge to the same longrun growth rate. Estimating the cointegrating relationship between world output and reserves on Australian data yields similar estimates:

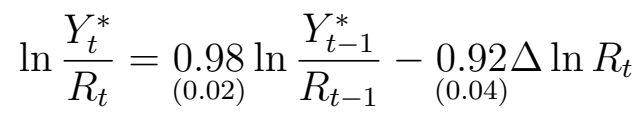

\subsection{GMM Estimation}

Exploration costs, investment adjustment costs, the risk premium parameter, the persistence of commodity price shocks, and the Taylor rule coefficients on inflation and the lagged interest rate affect the dynamics of the models only and so are estimated. We use a general method of moments (GMM) matching procedure, that minimises a measure of distance between the model-implied impulse response functions (IRFs) and those from an empirical VAR. Following Christiano et al. (2005), the estimated parameters minimise:

$$
J=\min _{\theta}\left[g^{\text {Model }}(\theta)-\widehat{g}^{V A R}\right]^{\prime} W^{-1}\left[g^{\text {Model }}(\theta)-\widehat{g}^{V A R}\right]
$$

where $\theta=\left[\phi_{m c}, \kappa, \phi_{b}, A_{r}, \rho_{\pi}, \rho_{i}\right]^{\prime}$ is the parameter vector to be estimated, and $\widehat{g}^{V A R}$ $\left(g^{\text {Model }}(\theta)\right)$ are the empirical VAR (model-implied) IRFs to be matched. $W$ is a diagonal weighting matrix containing the variances associated with the confidence intervals for each IRF point, as estimated by the empirical VAR. Ten equidistant moments are used for each IRF matched and cover a 20-year response horizon. With this choice the parameters estimated ensure that the model-implied IRFs lie within the confidence intervals for the empirical VAR as far as possible (Figure 3).

\footnotetext{
${ }^{43}$ The model-implied quarterly elasticity of cost-push inflation is similar to estimates from a panelVAR for G7 countries (Gerard, 2012) and from a New Keynesian Phillips curve for Australia (as estimated in the same paper). It is also in line with estimates in Hamilton (2003).
} 
The empirical-VAR used for the matching process is: ${ }^{44}$

$$
\mathbf{A}_{0} \mathbf{z}_{t}=\Gamma \mathbf{z}_{t-1}+\mathbf{e}_{t}
$$

where $\mathbf{z}_{t}$ is the vector of observables relating to the IRFs being matched - commodity prices, the real exchange rate, the ratio of domestic production to reserves, the ratio of mining investment to reserves and inflation. This VAR is estimated on Australian data and to identify the IRFs in response to commodity price shocks we assume that $\mathbf{A}_{0}$ is lower triangular where commodity prices are ordered first. ${ }^{45}$ That is, shocks to commodity price shocks are contemporaneously uncorrelated with shocks to domestic variables and the real exchange rate and so the Australian economy is small in the short-run. We separately estimate the endogenous and exogenous reserves models, using the GMM matching procedure in each case. ${ }^{46}$

\subsubsection{Matched Impulse Responses to a Commodity Price Shock}

Figure 3 highlights the IRFs from the empirical VAR and from the models. Overall, the endogenous model is better able to match the empirical data with the estimated parameters resulting in a minimised objective criterion of 44.50 as opposed to 88.93 at the exogenous parameter estimates (Table 5). The endogenous model captures a persistent boom in the ratio of mining investment to reserves, an appreciation of the real exchange rate and little change in non-mining production in the short-run. In contrast, the exogenous reserve model underestimates the appreciation of the real exchange rate (is 2.8 standard deviations below the empirical VAR in the first period), and and overestimates the contraction in the ratio of non-mining output to reserves (is 5 standard deviations below the empirical VAR). The exogenous

\footnotetext{
${ }^{44}$ We include a deterministic time trend and constant. Similar estimates are obtained using a HP-filter or first-differenced data. For a complete description of the data see the online Appendix.

${ }^{45}$ Since commodity prices are ordered first and we are only interested in shocks to them, our results are invariant to any change in the subsequent ordering of variables.

${ }^{46}$ As discussed in Ravenna (2007), with unobserved state variables each models' solution admits a VARMA representation and it is not clear whether the model-implied IRFs can be well approximated by those obtained from a VAR with finite lags. To verify that the VAR approximation used is appropriate, we simulate the variables used in estimation from both the endogenous and exogenous reserves models and then estimate the equivalent empirical VAR on each simulated data set. As shown in the online Appendix, the empirical VAR can approximately recover the true model-theoretic IRFs in each case. The reason that this is possible is that by using reserves (a key state variable in the model) to deflate domestic production and investment, long-run cointegrating relationships that are implied by the model are also preserved in the empirical VAR.
} 
Figure 3: Estimated and Emprical IRFs
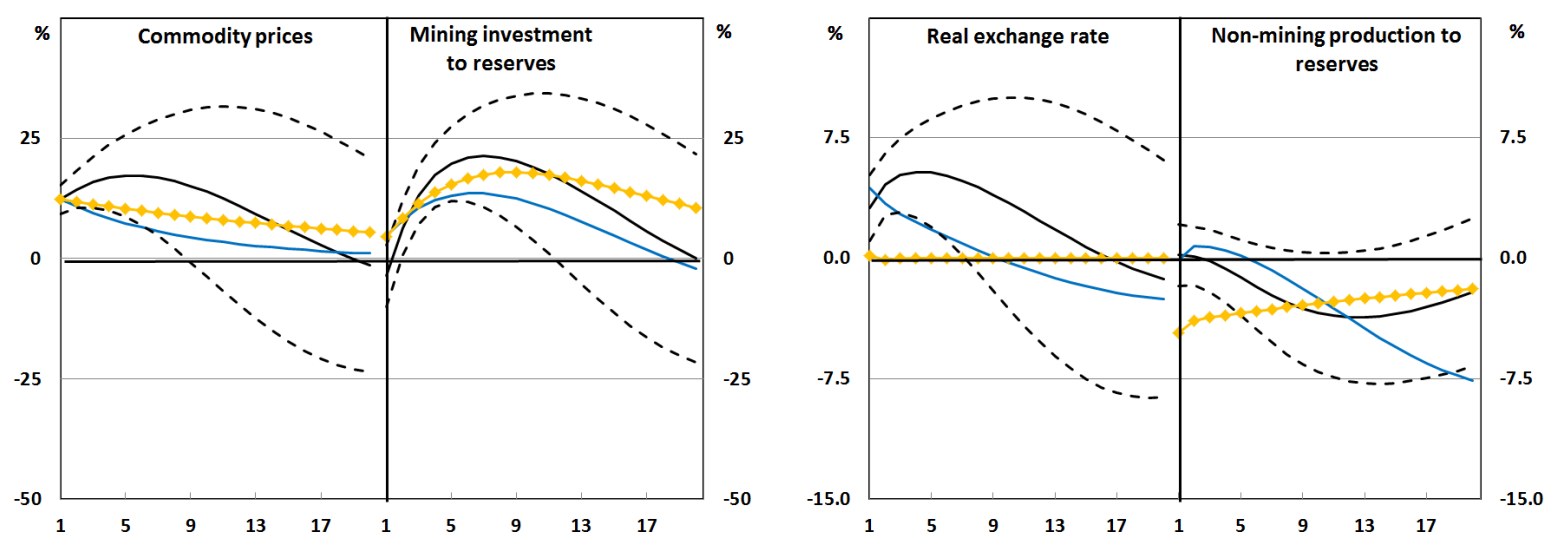

Notes: Each IRF is measured in terms of the percentage deviation from its sample mean (or percentage point deviation where appropriate); ninety five percent confidence intervals are reported for the empirical VAR.

model also over overestimates overestimates the persistence of the boom in mining investment. Since the near-term IRFs are estimated with the most precision and have narrower confidence bands, these moments are given the most weight in the GMM matching procedure and this contributes to the better fit of the endogenous model.

\subsubsection{The GMM Estimates}

Table 5 reports the estimated coefficients. The risk premium for the exogenous model is 16.25, much higher than the endogenous model at 0.01 and corresponding estimates in the literature that typically span 0.001 to 0.30 (Adolfson et al., 2007; Jääskelä and Nimark, 2011; García and González, 2013). A high estimate in the exogenous model is required to generate volatility in the real exchange, but even with this degree of sensitivity in foreign borrowing costs the exogenous model still struggles to match the appreciation of the real exchange rate in response to a commodity price shock (Figure 3). ${ }^{47}$

Both models have similar estimates for investment adjustment costs at a little over 7, with standard estimates ranging from about 2 to 10 (de Resende et al., 2010; Rees et al., 2015). Both models also estimate a high degree persistence in the process for commodity prices, with $\mathrm{AR}(1)$ coefficients of 0.96 and 0.88 respectively, which is

\footnotetext{
${ }^{47}$ Part of the reason the exogenous model is higher than corresponding Bayesian DSGE estimates is the use of priors in the latter that centre the posterior distribution towards much lower estimates (see for example Rees et al. (2015)), and that we are using a limited information approach that directly targets the response of the real exchange rate to a commodity price shock.
} 
also comparable to existing estimates that range from 0.81 to 0.96 depending on the small commodity exporter of interest (Rees and Gómez-González, 2013).

Table 5: GMM Estimates

\begin{tabular}{lccc}
\hline Description & Coefficient & $\begin{array}{c}\text { Exogenous } \\
\text { Model }\end{array}$ & $\begin{array}{c}\text { Endogenous } \\
\text { Model }\end{array}$ \\
\hline Risk premium & $\varphi_{b}$ & 16.25 & 0.01 \\
Exploration costs parameter & & $(4.81)$ & $(0.005)$ \\
& $\phi_{m c}$ & -- & 0.09 \\
Investment costs parameter & $\kappa$ & 7.29 & $(0.01)$ \\
& & $(1.86)$ & 7.59 \\
AR(1) parameter (commodity prices) & $A_{r}$ & 0.96 & 0.88 \\
& & $(0.01)$ & $(0.01)$ \\
Interest rate smoothing (Taylor rule) & $\rho_{i}$ & 0.18 & 0.14 \\
& & $(0.36)$ & $(0.16)$ \\
Weight on inflation (Taylor rule) & $\rho_{\pi}$ & 1.49 & 2.81 \\
& & $(0.16)$ & $(0.43)$ \\
\hline Minimised GMM criterion & $J$ & 88.93 & 45.70 \\
\hline
\end{tabular}

Turning to the interest rate rule, the coefficients on the lagged interest rate are similar across models at 0.18 and 0.14 for the exogenous and endogenous models. However, the weight on inflation in the endogenous model is higher at 2.81, as compared to 1.49. With greater propagation of commodity price shocks in the endogenous model, a more activist monetary policy is required to match the IRFs from the empirical VAR. These estimates are broadly similar to those obtained from Bayesian small open economy DSGE models for Australia, Canada and New Zealand with coefficients on inflation ranging from 1.80 to $2.33 .^{48}$

To provide additional context, we also estimate Taylor rules on annual data for Australia, Canada and Norway, which captures the average interest rate reaction to all shocks hitting the economy and not just commodity price shocks (Table 6). The empirical estimates highlight that the average response to inflation is comparable. Interestingly, there is little evidence to suggest that monetary policy responds to volatility in the real exchange rate, commodity price growth, or changes in the ratio of domestic output to reserves in either Australia, Canada or Norway. Tests of the null that these coefficients are jointly zero cannot be rejected in any of these economies.

\footnotetext{
${ }^{48}$ See for example Justiniano and Preston (2010) and the references cited therein.
} 
Table 6: Taylor Rule Estimates for Australia, Canada and Norway

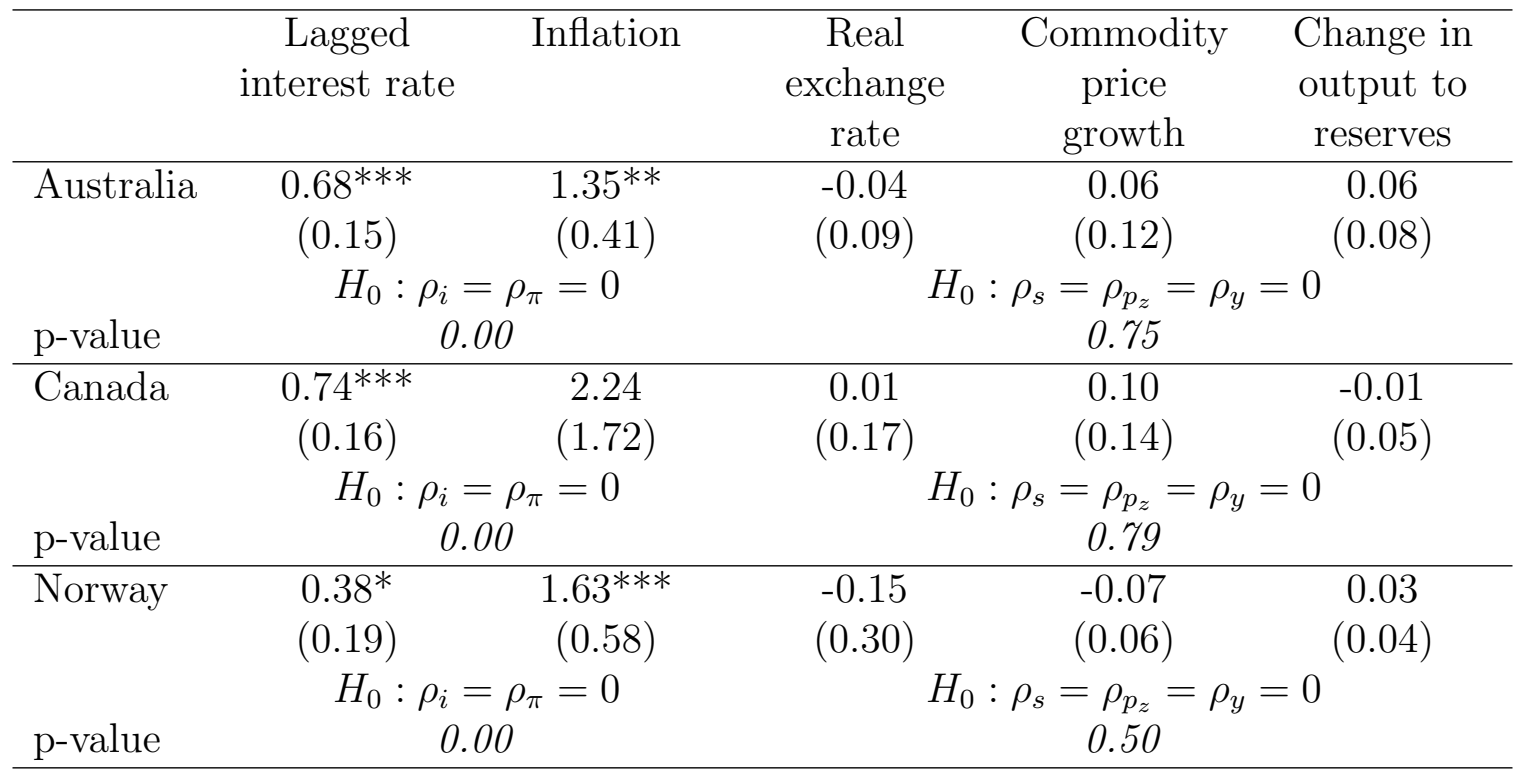

\section{The Effects of Exploration and Depletion}

We now compare the differences between the two models solely due to exploration and depletion. We do this using the parameterisation of the endogenous reserves model and then "turning off" the equations for exploration and depletion. ${ }^{49}$ Figure 4 reports the resource sector's response to a one standard deviation (12 per cent) increase in commodity prices in the economy with exploration and depletion, and without them. It highlights a much larger response when reserves are endogenous.

The responses of mining investment and extraction are two to three times as large, with the maximal response of investment and extraction being an increase of 17 (8) per cent and 10 (3) per cent for the endogenous (exogenous) reserve economies. The responses of investment and extraction lag the increase in price and the effects on exploration and reserves are highly persistent. Initially, exploration costs increase as both exploration activity and the aggregate stock of reserves rise. However, scarcity when exploring for new reserves becomes more important over time with the rising stock of aggregate reserves contributing to higher costs of exploration.

The marginal values of reserves rise by less with exploration, consistent with the discovery of new reserve deposits. However, resource sector revenue and profit are

\footnotetext{
${ }^{49}$ We could alternatively focus on the parameterisation of the exogenous model for the benchmark and turn on exploration and depletion. The results are similar.
} 
both more volatile as firms initially borrow more to fund increases in investment and exploration activity. These investments delay the peak extraction response and better matches the correlation between price growth and production growth as discussed earlier in Section 2.

The amplification in the model arises since exploration results in a permanent increase in future extraction possibilities. As newly found reserves never depreciate and are complementary to labour and capital in production, the marginal productivity of resource extraction is raised in all periods, or until the full amount of any newly discovered reserves are extracted. Even small changes in reserves can have long-term effects on a resource firms' productivity leading to larger and more persistent increases in extraction, investment and labour demand.

Figure 5 shows the responses for the rest of the domestic economy. The price shock is transmitted to domestic activity with larger declines in consumption and nonresource exports, and a significant appreciation of the real exchange rate. The decline in consumption reflects rising interest rates, domestic and foreign (the latter due to a higher risk premium), as resource firms borrow to fund increases in exploration and investment. The appreciation of the real exchange rate and higher domestic costs of production crowd out production of non-resource exports. With a higher marginal product of labour in the resource sector as opposed to the non-traded sector, wages rise in the former and fall in the latter inducing a flow of labour across sectors.

Overall, the effect on domestic production is positive. This stems from the assumption that exploration absorbs non-traded inputs, but could be equivalently generated by assuming that either investment or resource extraction require non-traded services in the installation capital or extraction of reserves. In short, endogenous reserves have a positive net effect on overall demand, generate a commodity currency and a reallocation of goods and labour (the "Dutch Disease").

When reserves are exogenous the effect on domestic production is contractionary, there is little change in the real exchange rate and there is much less reallocation of goods and labour across sectors. Even if we allowed for resource sector extraction to absorb non-traded services, we would still estimate a contraction in overall domestic production. The amplification of shock to commodity prices on the resource sector is simply too small. 
Figure 4: Resource Sector Response to a Shock to Commodity Prices

Commodity prices, reserves and exploration
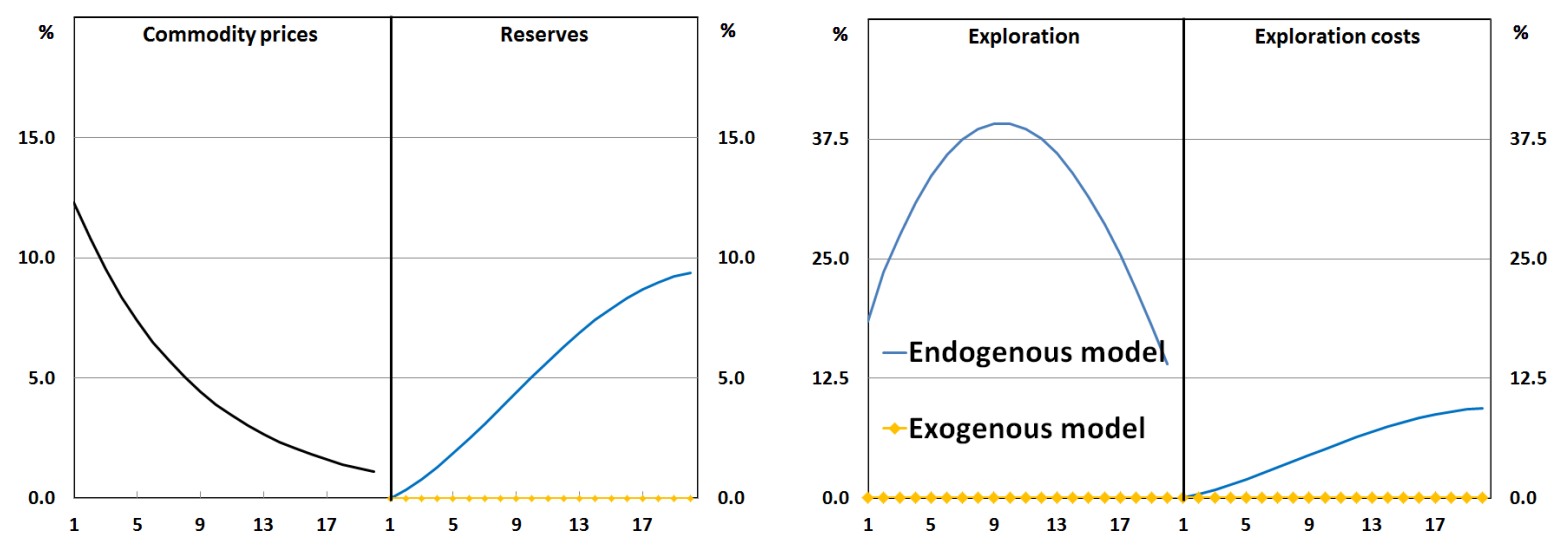

Investment, extraction and the labour market
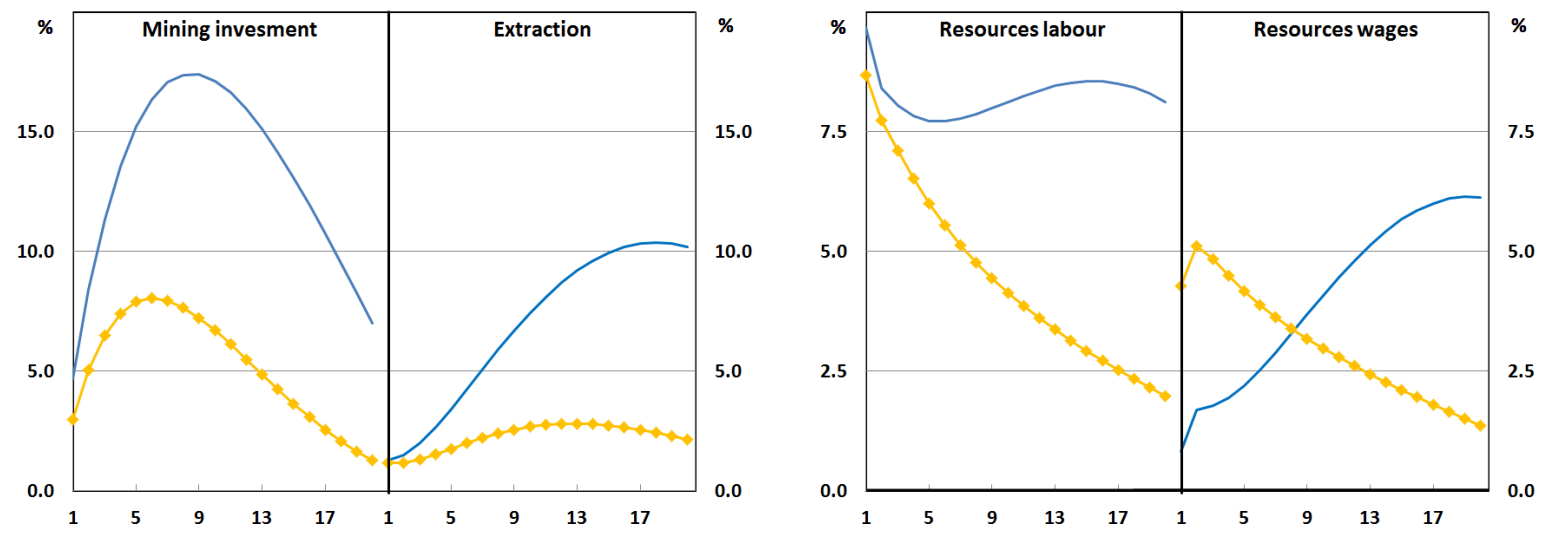

Shadow prices, revenue and profits
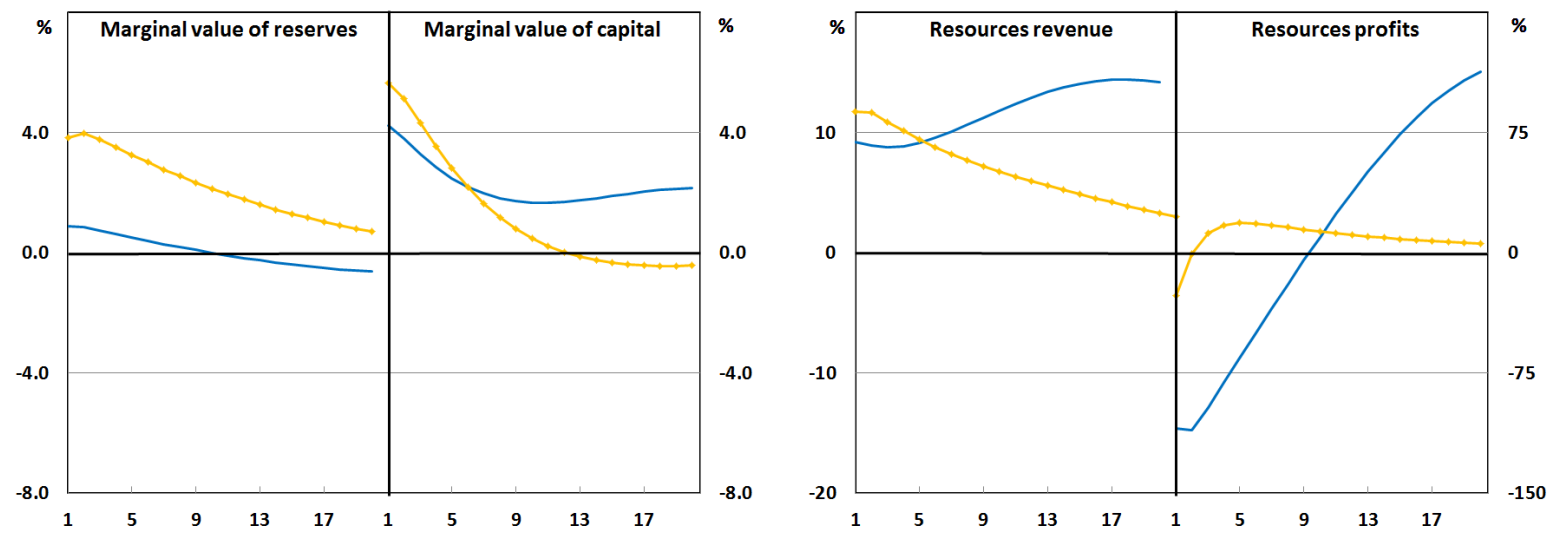

Notes: Each IRF is measured in terms of the percentage deviation from its steady state value. The shock is a one standard deviation increase in commodity prices. 
Figure 5: Domestic Economy Response to a Shock to Commodity Prices

Quantities and the real exchange rate
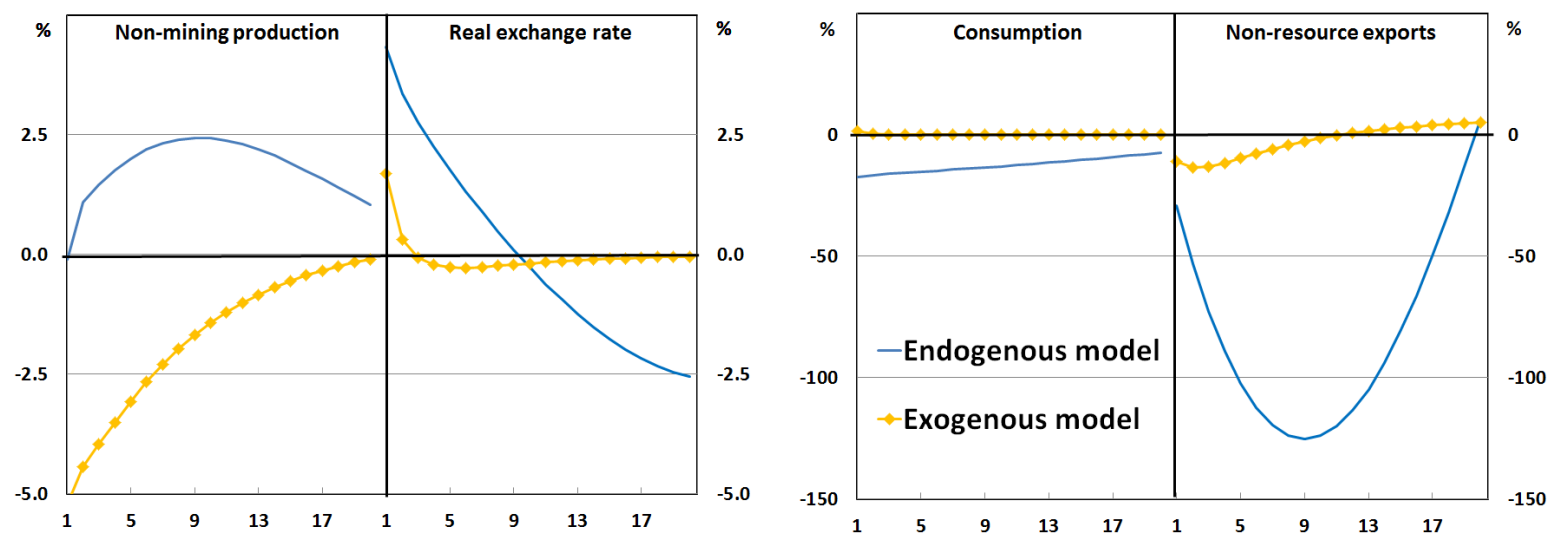

Wages and prices
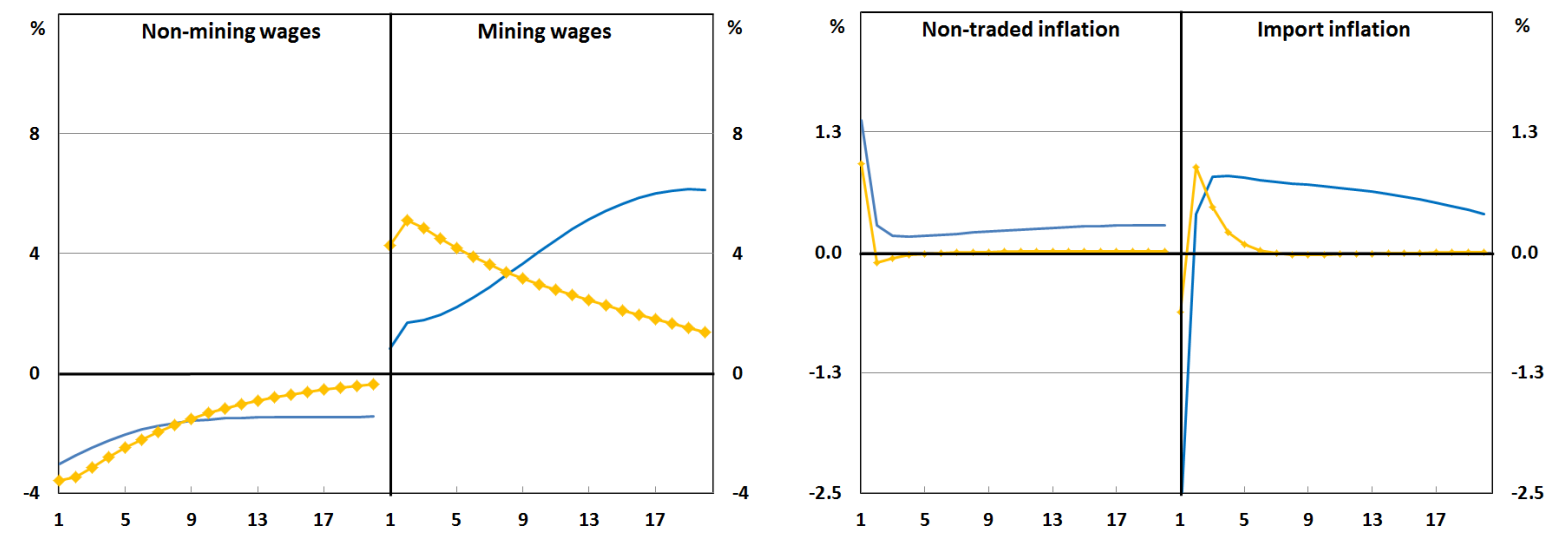

Interest rates, inflation and debt
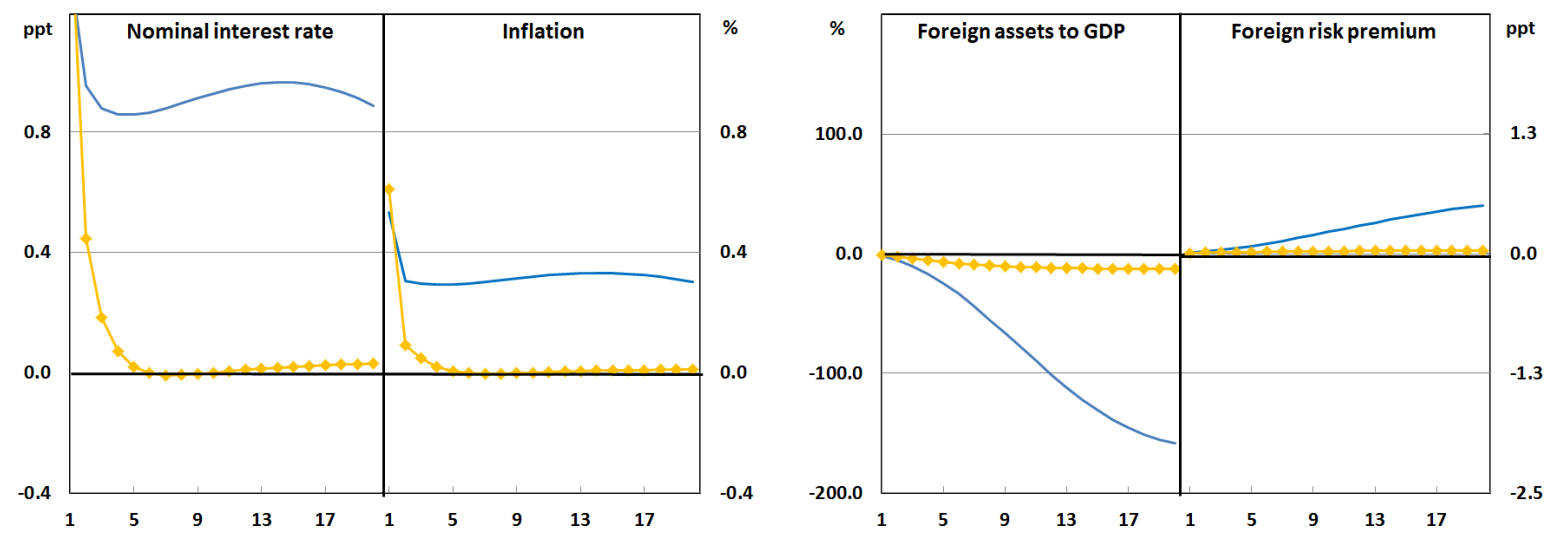

Notes: Each IRF is measured in terms of the percentage deviation from its steady state value. The shock is a one standard deviation increase in commodity prices. 


\subsection{Welfare and Optimal Policy Rules}

There are two implications of endogenous reserves: on the one hand, they increase sectoral reallocation (the "resource movement effect"); on the other, they imply higher wealth tied to the discovery of new reserves (the "spending effect"). In the presence of frictions including sector-specific price and wage rigidities, a risk premium on foreign borrowing, and an inability to fully insure against commodity price shocks through asset markets, it is not clear a priori how commodity price volatility will affect welfare. We now explore this question and the implications for optimal policy.

Focusing on the unconditional mean of household utility (household welfare), ${ }^{50}$ we evaluate the percentage of steady state consumption that equalises mean household welfare in a stochastic economy that has commodity price volatility (with a standard deviation of price of 1 per cent), and in an economy without price volatility, the non-stochastic steady state. ${ }^{1}$ At the benchmark calibration, households are willing to forgo 2.65 per cent of steady state consumption growth to avoid commodity price volatility in the model with exploration and depletion, much larger than the 0.004 per cent implied in the standard model. Endogenous reserves present a much 'gloomier' view of commodity price volatility than in the standard model. Given the magnitude of these welfare differences, a natural question is whether optimal policy rules be used to mitigate these effects and is there any difference in optimal policy with and without endogenous reserves?

\subsubsection{Optimal Interest-Rate Rules}

Our initial focus is on monetary policy - optimal interest rate rules - where the nominal interest rate is allowed to respond to variation in inflation, the real exchange rate, commodity prices, the level of domestic production (deflated by reserves) and the lagged interest rate: ${ }^{52}$

\footnotetext{
${ }^{50}$ That is,

$$
\mathcal{W}=\mathbb{E}\left[\sum_{t=t_{0}}^{\infty} \beta^{t-t_{0}}\left(\frac{\left(\frac{C_{t}}{V_{t}}\right)^{1-\xi_{c}}}{1-\xi_{c}}-\varsigma\left(\frac{H_{t}^{n^{\frac{1}{\gamma_{h}}}}}{H^{n}}+\frac{H_{t}^{r^{\frac{1}{\gamma_{h}}}}}{H^{r}}\right)^{\xi_{h} \gamma_{h}}\right)\right]
$$

${ }^{51}$ We use second-order perturbation methods to evaluate the effects of a change in volatility relative to the non-stochastic steady state.

${ }^{52}$ These variables have been emphasised in previous literature. We use the ratio of domestic production to reserves as this is stationary while the level of domestic production is not. Similar results
} 


$$
\widehat{i}_{t}=\rho_{i} \widehat{i}_{t-1}+\left(1-\rho_{i}\right)\left(\rho_{\pi} \widehat{\pi}_{t}^{c}+\rho_{y} \widehat{\left(\frac{Y_{t}}{R_{t}}\right)}+\rho_{s} \widehat{\left(\frac{S_{t}}{P_{t}^{c}}\right)}+\rho_{r} \widehat{P}_{t}^{r^{*}}\right)
$$

Hats denote log deviations from steady state and the coefficients in the interest-rate rule, $\left\{\rho_{i}, \rho_{\pi}, \rho_{y}, \rho_{s}, \rho_{r}\right\}$, are selected to maximise a second-order approximation of household welfare.

Table 7 reports the optimised coefficients for the endogenous and exogenous reserves models. In the case of exogenous reserves, the optimal weight on inflation is 1 , and there is no incentive to respond to volatility in the ratio of domestic production to reserves, the real exchange rate or commodity prices. With endogenous reserves, the optimal weight on inflation remains 1, but there is now an incentive to loosen interest rates in response to any decline in the ratio of non-mining output to reserves. This might help to mitigate against any sectoral reallocation or Dutch-Disease following a commodity price boom. Interestingly, it is not optimal to lean heavily against inflation a point that we will return to below.

The welfare losses in the endogenous and exogenous reserve economies with commodity price volatility and under an optimised interest rate rule are 1.10 per cent (a gain of 1.46 per cent relative to the model-implied estimates of the interest rate rule) and 0.0007 per cent respectively (a gain of 0.003 per cent). With endogenous reserves, there is still a substantial welfare gap even under an optimised interest rate rule. With exogenous reserves the welfare gap is much smaller and an optimised interest rate can insulate household welfare.

\section{Table 7: Optimised Interest Rate Rule Coefficients}

\begin{tabular}{lcc}
\hline & Exogenous Model & Endogenous Model \\
\hline Inflation & 1.00 & 1.00 \\
Output deflated & 0.006 & 0.28 \\
Real exchange rate & -0.003 & 0.002 \\
Natural commodity prices & -0.001 & 0.001 \\
Lagged interest rate & 0.00 & 0.00 \\
\hline Welfare loss (per cent) & 0.0007 & 1.10 \\
Notes: Welfare is measured as the percentage of steady state consumption that households would be \\
willing to forgo when moving from an economy without commodity price volatility to an economy \\
with commodity price volatility under each optimised interest rate rule.
\end{tabular}

are obtained if an alternative stationary transformation, such as growth in domestic production, is used. 


\subsubsection{Optimal Taxation Rules}

Monetary policy is not the only way that SCEs smooth the effects of commodity price volatility. Many also levy taxes on the resource sector and change them during large commodity price cycles. For example, during the most recent price boom a number of SCEs including Australia have either introduced new commodity taxes, increased tax rates, expanded the set of commodities taxed or modified tax rates to be "sliding rate" schedules that condition on observed prices (Hogan and McCallum, 2010). With this in mind, we also consider a simple class of price-contingent taxation rules:

$$
\widehat{1-\tau_{t}}=\rho_{\tau}\left(\widehat{1-\tau_{t-1}}\right)-\sigma_{\tau} \varepsilon_{t}^{r^{*}}
$$

where $\widehat{1-\tau_{t}}$ is the log deviation from steady state in the after-tax return, measured in domestic currency terms, and $\varepsilon_{t}^{r^{*}}$ is the commodity price shock. The parameter $\sigma_{\tau}$ measures the sensitivity of the after-tax return to changes in commodity prices and $\rho_{\tau}$ captures the persistence of any tax change. These two parameters are chosen to jointly maximise household welfare. ${ }^{53}$ We assume tax collections are rebated to households via a lump-sum payment. ${ }^{54}$

This class of rules allows the announcement of a tax (or subsidy) on the resource sector that is linked to price and implemented in the same year as a price shock. By allowing the tax rules to condition on changes in commodity prices, they are on the same footing as interest-rate rules in their ability to smooth the economy. We consider three tax policies:

(i) a profit (resource rent) tax;

$$
\left(1-\tau_{t}\right)\left(S_{t} P_{t}^{r^{*}} X_{t}-W_{t}^{r} H_{t}^{r}-S_{t} P_{t}^{*} I_{t}-C\left(D_{t}, \widetilde{R}_{t}\right)\right)
$$

(ii) a tax per unit of revenue (ad valorem royalty);

$$
\left(1-\tau_{t}\right) S_{t} P_{t}^{r^{*}} X_{t}-W_{t}^{r} H_{t}^{r}-S_{t} P_{t}^{*} I_{t}-C\left(D_{t}, \widetilde{R}_{t}\right)
$$

\footnotetext{
${ }^{53}$ Again, we maximise a second-order approximation of household welfare. When searching for the optimal coefficients, we restrict $\rho_{\tau} \in(0,1)$ and set the steady state after-tax return to one.

${ }^{54}$ We do allow the after-tax return to be greater than one implying a subsidy in the case that commodity prices decline.
} 
(iii) and a tax on the value of reserves (reserves tax) ${ }^{55}$

$$
S_{t} P_{t}^{r^{*}} X_{t}-W_{t}^{r} H_{t}^{r}-S_{t} P_{t}^{*} I_{t}-C\left(D_{t}, \widetilde{R}_{t}\right)-\tau_{t} Q_{t}^{R} R_{t}
$$

Steady state equivalents of these taxes have been studied in natural resources literature - Gamponia and Mendelsohn (1985), Yücel (1989), Deacon (1993) and Boadway and Keen (2015). Empirically, resource rent taxes have been used in Norway and the UK, and ad valorem royalties have been used in Australia, Canada and the US (Otto et al., 2006). However, it is also not uncommon for different regions within jurisdictions to use different tax regimes, or for some regions to use hybrid taxes structures that combine elements of both a resource rent tax and an ad valorem royalty. Taxes on the value of reserves held are less common in practice, but they have an interesting implication in the model with exogenous reserves as we will see below.

Table 8 reports the coefficients for each optimised tax rule. Comparing welfare across the three different rules when reserves are endogenous, the optimal tax rule is the ad valorem royalty, which is able to fully insulate the economy against the adverse effects of commodity price volatility. Figure 6 highlights the intuition for this result, showing key IRFs under the three tax policies. It highlights that under an optimal ad valorem royalty, the effects on resource sector activity, including investment and extraction, consumption volatility and the reallocation of labour across sectors are minimised.

By increasing taxes on revenue when commodity prices rise, this insulates resource firms from the direct effects of a commodity price shock. ${ }^{56}$ This reduces the incentive for resource firms to change their optimal extraction, investment, exploration and labour demand decisions. Moreover, since tax revenues are rebated to households' lump-sum, there is no additional distortion to household decisions.

\footnotetext{
${ }^{55}$ With exogenous reserves it should be noted that the value of the tax liability is not fixed (even if reserves are). The reason is that the marginal value (price of reserves) still fluctuates when reserves are held fixed.

${ }^{56}$ This response is efficient because volatility in commodity prices is isomorphic to exogenous shocks to revenue from a resources firms' perspective. More precisely, for any given sequence of commodity price shocks, there exists a sequence of ad valorem royalties that can precisely undo the direct effects of these shocks on firm revenue (see Equation 31).
} 


\section{Figure 6: Responses under Optimal Taxation Rules Endogenous Reserves}
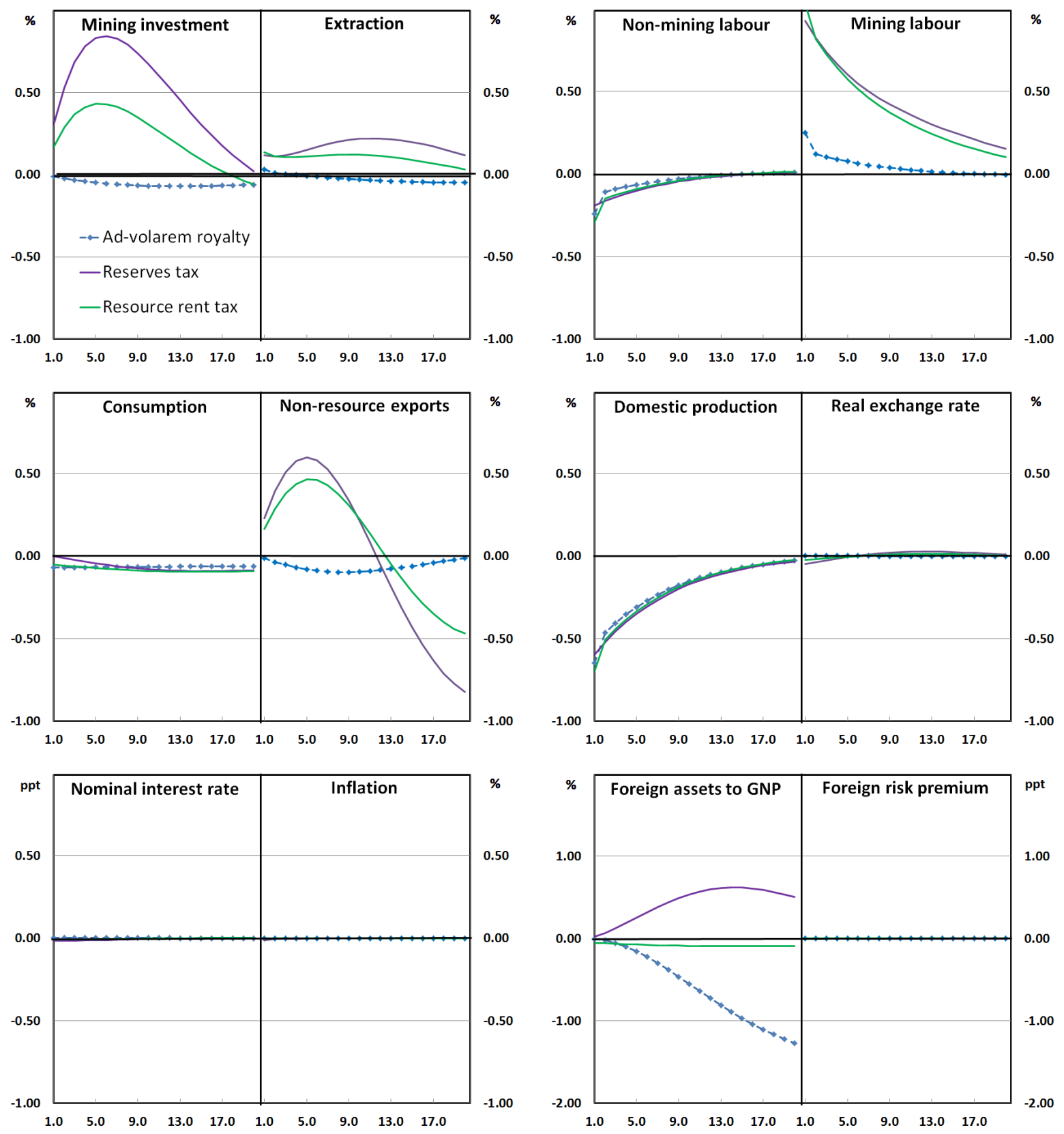

Notes: The impulse is a one standard deviation increase in commodity prices. Responses are displayed under each of the optimised tax rules reported in Table 8. 
Table 8: Optimised Tax Rule Coefficients

\begin{tabular}{lcc}
\hline & Exogenous Model & Endogenous Model \\
\hline & Resource rent tax \\
Autoregressive coefficient & 0.97 & 0.91 \\
Tax elasticity & 14.07 & -0.53 \\
Welfare & 99.97 & 99.98 \\
\hline \multicolumn{3}{c}{} \\
Autoregressive coefficient & Ad valorem royalty \\
Tax elasticity & 0.83 & 0.88 \\
Welfare & 11.26 & 1.01 \\
& 99.99 & 100 \\
Autoregressive coefficient & Reserves tax \\
Tax elasticity & 0.99 & 0.93 \\
Welfare & 11.13 & 0.05 \\
Notes: 100 less the normalised welfare figures reported denotes the amount of consumption that \\
households would be willing to forgo when moving from an economy without commodity price volatility \\
to an economy with commodity price volatility (a standard deviation of 1 per cent) under each \\
optimised taxation rule.
\end{tabular}

Optimal resource rent and reserve taxes are not as efficient at stabilising welfare. They imply higher volatility in the mining sector when commodity prices rise as it is optimal for resource firms to become more capital intensive to reduce their tax liability (see Equations 30 and 32). ${ }^{57}$ A positive commodity price shock leads to higher mining investment and extraction, which then spills over to domestic activity, the real exchange rate and more reallocation of labour and goods across sectors (Figure 6). Overall though, the rules lead to similar welfare outcomes and any one of them can mitigate the effects of commodity price volatility on welfare.

With exogenous reserves, the findings are quite different. In that case a highly persistent reserves tax becomes optimal because, absent the business cycle volatility generated by endogenous reserves, it is optimal to expropriate the resource rent associated with domestic reserves and redistribute this directly as a lump transfer to households. ${ }^{58}$ This is the unique case in the economies considered in which households actually prefer commodity price volatility that can raise the value of the resource

\footnotetext{
${ }^{57}$ Note that the optimal resource rent tax is negative (a subsidy). This reflects the tilting of production decisions - by initially subsidising profits, with the value of the subsidy declining thereafter, firms bring forward extraction. Incentives to explore and invest are, however, attenuated with less spillover to the rest of the economy. Under the optimal ad valorem royalty, there is less tilting of production decisions and a positive tax is optimal.

${ }^{58}$ In effect, the reserve tax reduces the foreign sector profit share and redistributes this to domestic households.
} 
rents, and thus the value of any lump sum distribution to them.

\subsection{Is Monetary or Taxation Policy Optimal?}

How does the optimal interest rate rules compare with the optimal tax rule in the economy with exploration and depletion? Comparing welfare outcomes in the third column of Tables 7 and 8, it is clear that an optimal interest rate rule is less efficient than the optimal ad valorem royalty (a welfare loss of about 1.09 per cent comparatively). Figure 7 highlights the source of the difference. Compared with the optimal royalty, the optimal interest rate rule results in more sectoral reallocation of goods and labour, higher inflation and higher consumption volatility.

In fact, only a small increase in interest rates is optimal in response to a positive commodity price shock. Raising interest rates to offset the expansion of the resource sector comes at the expense of more pronounced contractions in domestic production, non-resource exports and consumption. The comparative inefficiency of interest rates as a stabilisation tool is is an example of a blunt-instrument critique. Since raising interest rates contracts activity in all sectors and not just the resource sector, this lack of specificity leads to increased volatility in the non-resource sector and interest rates become less efficient in stabilising the effects of commodity price shocks. Although a similar argument could apply in the economy with exogenous reserves, quantitatively this is not the case. The welfare loss of commodity price volatility is small and an optimised interest rate can almost fully eliminate this loss (Table 8, column two).

\section{Conclusion}

Integrating insights from natural resources literature is important for capturing the effects of commodity price shocks quantitatively. We show that a model with exploration and depletion better accounts for the effects of commodity price shocks on the resource and non-resource sectors, including spillovers between the two. Incorporating a minimal set of frictions in order to match the effects of commodity price shocks on a prototypical SCE (Australia), we show that endogenous supply of reserves has important welfare and optimal policy implications. In contrast to the standard assumption of exogenous reserves, commodity price volatility has a larger effect on household welfare when supply is endogenous and reduces the efficiency of monetary 


\section{Figure 7: Responses under Optimal Monetary and Taxation Policy Endogenous Reserves}
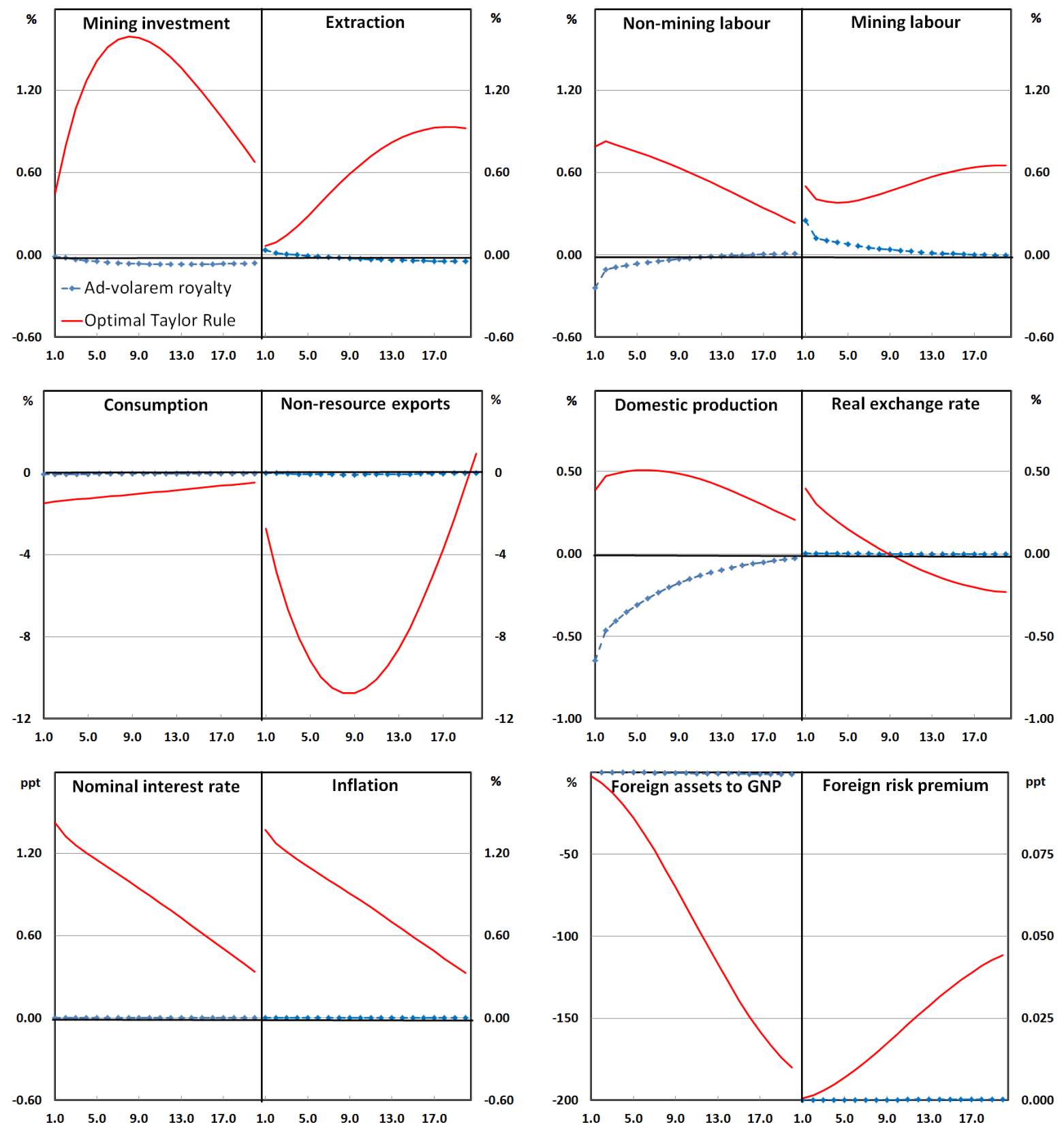

Notes: The impulse is a one standard deviation increase in commodity prices. Responses are displayed under optimised Taylor rule and under an optimal ad valorem royalty. 
policy when stabilising the effects of commodity price shocks. Alternatively, we find that simple tax rules that condition on price remain an efficient policy response, both when reserves are exogenous and when they are endogenous.

We conclude by providing brief comments on whether optimal tax rules are implementable. First, they are simple. Given the similarity observed in the persistence of commodity prices and the persistence of the optimal tax rule - a simple indexation rule that makes changes in the tax schedule proportional to price provides a good approximation of an optimal tax rule. Such a rule is transparent, easy to communicate and has the natural interpretation of risk sharing between the fiscal authority and the resource sector. Second, since the resource sector must be subsidised when prices fall, this can contribute to better fiscal planning. ${ }^{59}$ Third, tax rules that condition on price, such as sliding tax schedules, are becoming more common. Our work provides one rationalisation for the move in that direction.

\footnotetext{
${ }^{59}$ If fiscal authorities not only experience revenue windfalls when prices are high, but must also reduce taxes when prices are low, this will reduce the incentive to spend short-term windfall gains. Empirically, fiscal restraint can help to explain why some SCEs manage commodity price volatility better than others (Pieschacón, 2012).
} 


\section{Acknowledgements}

We appreciate feedback from the Editor and referees, Guilherme de Almeida Bandeira, Martin Berka, Adam Cagliarini, Renaud Coulomb, Richard Dennis, Alexandra Heath, Mariano Kulish, Adrian Pagan, Bruce Preston, Giorgio Primiceri, Tim Robinson, Penny Smith, Lawrence Uren, Samuel Wills and seminar participants at the Workshop of the Australasian Macroeconomics Society, Workshop on Macroeconomic Dynamics, Reserve Bank of Australia, Monash University, University of Melbourne and University of Technology Sydney. This paper is a substantial revision of a Reserve Bank of Australia Research Discussion Paper entitled "Reserves of Natural Resources in a Small Open Economy". The views expressed in this paper and the earlier draft are the authors and do not necessarily reflect the views of the Reserve Bank of Australia. Use of any results from this paper should clearly attribute the work to the authors and not to the Reserve Bank of Australia. 


\section{References}

Abel, A. B., 1990. Asset Prices Under Habit Formation and Catching up with the Joneses. The American Economic Review 80 (2), pp. 38-42.

Adolfson, M., Laséen, S., Lindé, J., Villani, M., 2007. Bayesian Estimation of an Open Economy DSGE Model with Incomplete Pass-through. Journal of International Economics 72 (2), pp. 481-511.

Aguiar, M., Gopinath, G., 2007. Emerging market business cycles: The cycle is the trend. Journal of Political Economy 115 (1), 69-102.

Alquist, R., Coibion, O., March 2014. Commodity-Price Comovement and Global Economic Activity. Working Paper 20003, National Bureau of Economic Research.

Anderson, S. T., Kellogg, R., Salant, S. W., July 2014. Hotelling Under Pressure. Working Paper 20280, National Bureau of Economic Research.

Arezki, R., Ramey, V. A., Sheng, L., January 2015. News Shocks in Open Economies: Evidence from Giant Oil Discoveries. Working Paper 20857, National Bureau of Economic Research.

Bems, R., de Carvalho Filho, I., 2011. The Current Account and Precautionary Savings for Exporters of Exhaustible Resources. Journal of International Economics 84 (1), pp. $48-64$.

Benedict, C., Crucini, M. J., Landry, A., 2016. On What States Do Prices Depend? Answers From Ecuador. Working Paper 22506, National Bureau of Economic Research.

Benigno, G., Thoenissen, C., 2008. Consumption and Real Exchange Rates with Incomplete Markets and Non-traded Goods. Journal of International Money and Finance 27 (6), pp. 926-948.

Benkhodja, M. T., 2014. Monetary Policy and the Dutch Disease Effect in an Oil Exporting Economy. International Economics 138, pp. 78-102. 
Bergholt, D., Jul. 2014. Monetary Policy in Oil Exporting Economies. Working Paper No. 5/2014, Centre for Applied Macro- and Petroleum Eeconomics (CAMP), BI Norwegian Business School.

Berka, M., Crucini, M. J., Wang, C.-W., 2012. International Risk Sharing and Commodity Prices. The Canadian Journal of Economics / Revue canadienne d'Economique 45 (2), 417-447.

Bidarkota, P., Crucini, M. J., 2000. Commodity Prices and the Terms of Trade. Review of International Economics 8 (4), 647-666.

Bishop, J., September 2016. The Size and Frequency of Wage Changes. Article, Australian Bureau of Statistics.

Bishop, J., Rayner, V., 2013. Industry Dimensions of the Resource Boom: An InputOutput Analysis. Research Discussion Paper 2013-02, RBA.

Bjørnland, H. C., Thorsrud, L. A., 2016. Boom or Gloom? Examining the Dutch Disease in Two-speed Economies. The Economic Journal, forthcoming.

Boadway, R., Keen, M., 2015. Rent Taxes and Royalties in Designing Fiscal Regimes for Nonrenewable Resources. In: Handbook on the Economics of Natural Resources. Edward Elgar Publishing, Cheltenham, UK.

Bodenstein, M., Erceg, C. J., Guerrieri, L., 2011. Oil Shocks and External Adjustment. Journal of International Economics 83 (2), pp. 168-184.

Bohn, H., Deacon, R. T., 2000. Ownership Risk, Investment, and the Use of Natural Resources. The American Economic Review 90 (3), pp. 526-549.

Cairns, R. D., 1990. The Economics of Exploration For Non-renewable Resources. Journal of Economic Surveys 4 (4), 361-395.

Caputo, R., Chang, R., 2015. Commodity Prices and Macroeconomic Policy: An Overview. In: Caputo, R., Chang, R. (Eds.), Commodity Prices and Macroeconomic Policy. Central Bank of Chile. 
Carceles-Poveda, E., Coen-Pirani, D., 2010. Owning Capital or Being Shareholders: An Equivalence Result with Incomplete Markets. Review of Economic Dynamics 13 (3), pp. 537-558.

Cashin, P., Céspedes, L. F., Sahay, R., 2004. Commodity Currencies and the Real Exchange Rate. Journal of Development Economics 75 (1), pp. 239-268.

Cãto, L., Chang, R., 2013. Monetary Rules for Commodity Traders. IMF Economic Review 61 (1), pp. 52-91.

Chari, V., Kehoe, P. J., McGrattan, E. R., 2008. Are Structural VARs with Long-run Restrictions Useful in Developing Business Cycle Theory? Journal of Monetary Economics 55 (8), pp. 1337-1352.

Charnavoki, V., 2010. International Risk Sharing and Optimal Monetary Policy in a Small Commodity-Exporting Economy. Mimeo.

Charnavoki, V., Dolado, J. J., 2014. The Effects of Global Shocks on Small Commodity-Exporting Economies: Lessons from Canada. American Economic Journal: Macroeconomics 6 (2), pp. 207-237.

Chen, K., Crucini, M. J., 2016. Trends and cycles in small open economies: making the case for a general equilibrium approach. Journal of Economic Dynamics and Control 72, 159 - 168, trade and macroeconomics: new approaches to enduring puzzles.

Chen, Y., Rogoff, K., 2003. Commodity Currencies. Journal of International Economics 60 (1), pp. 133-160.

Christiano, L. J., Eichenbaum, M., Evans, C. L., 2005. Nominal Rigidities and the Dynamic Effects of a Shock to Monetary Policy. Journal of Political Economy $113(1)$, pp. 1-45.

Christiano, L. J., Eichenbaum, M., Vigfusson, R., 2007. Assessing Structural VARs. In: Acemoglu, D., Rogoff, K., Woodford, M. (Eds.), NBER Macroeconomics Annual 2006, Volume 21. MIT Press, pp. 1-106. 
Connolly, E., Orsmond, D., 2011. The Mining Industry: From Bust to Boom. Research Discussion Paper 2011-08, Reserve Bank of Australia.

Corden, W. M., 2012. The Dutch Disease in Australia: Policy Options for a ThreeSpeed Economy. Working Paper 2012-05, Melbourne Institute of Social and Applied Economic Research.

Corden, W. M., Neary, J. P., 1982. Booming Sector and De-Industrialisation in a Small Open Economy. The Economic Journal 92 (368), pp. 825-848.

Daniel, P., Keen, M., McPherson, C. (Eds.), 2010. The Taxation of Petroleum and Minerals: Principles, Problems and Practice. Routledge.

de Resende, C., Dib, A., Kichian, M., March 2010. Alternative Optimized Monetary Policy Rules in Multi-Sector Small Open Economies: The Role of Real Rigidities. Working Paper 2010-09, Bank of Canada.

Deacon, R. T., 1993. Taxation, Depletion, and Welfare: A Simulation Study of the U.S. Petroleum Resource. Journal of Environmental Economics and Management 24 (2), pp. 159-187.

Devarajan, S., Fisher, A. C., 1982. Exploration and Scarcity. Journal of Political Economy 90 (6), 1279-1290.

Dib, A., 2008. Welfare Effects of Commodity Price and Exchange Rate Volatilities in a Multi-Sector Small Open Economy Model. Working Paper 2008-8, Bank of Canada.

Erceg, C. J., Henderson, D. W., Levin, A. T., 2000. Optimal Monetary Policy with Staggered Wage and Price Contracts. Journal of Monetary Economics 46 (2), 281313.

Favilukis, J., Ludvigson, S. C., Nieuwerburgh, S. V., 2014. Foreign Ownership of U.S. Safe Assets: Good or Bad? Working Paper 19917, National Bureau of Economic Research.

Fornero, J., Kirchner, M., Yani, A., 2014. Terms of Trade Shocks and Investment in Commodity Exporting Economies. Banco Central de Chile Working Paper No. 773. 
Frankel, J., 2003. A Proposed Monetary Regime for Small Commodity Exporters: Peg the Export Price ('PEP'). International Finance 6 (1), pp. 61-88.

Gamponia, V., Mendelsohn, R., 1985. The Taxation of Exhaustible Resources. Quarterly Journal of Economics 100 (1), pp. 165-181.

Garcia, C., Gonzalez, W., 2010. Is More Exchange Rate Intervention Necessary in Small Open Economies? The Role of Risk Premium and Commodity Shocks. Working Paper 248, Georgetown University and Universidad Alberto Hurtado.

García, C. J., González, W. D., 2013. Exchange Rate Intervention in Small Open Economies: The Role of Risk Premium and Commodity Price Shocks. International Review of Economics and Finance 25, 424-447.

Gerard, H., Mar. 2012. Co-movement in Inflation. Research Discussion Paper 2012-01, Reserve Bank of Australia.

Gillitzer, C., Kearns, J., 2005. Long-term Patterns in Australia's Terms of Trade. Research Discussion Paper 2005-01, Reserve Bank of Australia.

Halvorsen, R., Layton, D. F. (Eds.), 2015. Handbook on the Economics of Natural Resources. Edward Elgar Publishing, Cheltenham, UK.

Hamilton, J. D., 1983. Oil and the Macroeconomy Since World War II. Journal of Political Economy 91 (2), pp. 228-248.

Hamilton, J. D., 2003. What is an Oil Shock? Journal of Econometrics 113 (2), pp. $363-398$.

Hansen, J., Gross, I., 2013. Reserves of Natural Resources in a Small Open Economy. Research Discussion Paper 2013-14, RBA.

Heal, G. M., 1993. Chapter 18 - The Optimal Use of Exhaustible Resources. In: Kneese, A. V., Sweeney, J. L. (Eds.), Handbook of Natural Resource and Energy Economics. Vol. 3. Elsevier, pp. 855-880.

Hevia, C., Nicolini, J. P., 2013. Optimal Devaluations. IMF Economic Review 61 (1), pp. $22-51$. 
Hogan, L., McCallum, R., 2010. Non-renewable Resource Taxation in Australia. ABARE Report - April 2010, prepared for the AFTS Review Panel, ABAREBRS, Canberra, October.

Hotelling, H., 1931. The Economics of Exhaustible Resources. Journal of Political Economy 39 (2), pp. 137-175.

Jääskelä, J., Smith, P., 2013. Terms of Trade Shocks: What Are They and What Do They Do? Economic Record 89 (285), pp. 145-159.

Jääskelä, J. P., Nimark, K., 2011. A Medium-Scale New Keynesian Open Economy Model of Australia. Economic Record 87 (276), pp. 11-36.

Jacks, D. S., 2013. From Boom to Bust: A Typology of Real Commodity Prices in the Long Run. Working Paper 18874, National Bureau of Economic Research.

Justiniano, A., Preston, B., 2010. Monetary Policy and Uncertainty in an Empirical Small Open-economy Model. Journal of Applied Econometrics 25 (1), 93-128.

URL http://dx.doi.org/10.1002/jae.1153

Kilian, L., 2008. Exogenous Oil Supply Shocks: How Big Are They and How Much Do They Matter for the U.S. Economy? The Review of Economics and Statistics 90 (2), pp. 216-240.

Lasserre, P., 1985. Discovery Costs as a Measure of Rent. The Canadian Journal of Economics / Revue canadienne d'Economique 18 (3), 474-483.

Livernois, J. R., Uhler, R. S., 1987. Extraction Costs and the Economics of Nonrenewable Resources. Journal of Political Economy 95 (1), 195-203.

Natal, J.-M., 2012. Monetary Policy Response to Oil Price Shocks. Journal of Money, Credit and Banking 44 (1), pp. 53-101.

Otto, J., Andrews, C., Cawood, F., Doggett, M., Guj, P., Stermole, F., Stermole, J., Tilton, J., 2006. Mining Royalties: A Global Study of Their Impact on Investors, Government, and Civil Society. The World Bank. 
Pfaffenzeller, S., Newbold, P., Rayner, A., 2007. A Short Note on Updating the Grilli and Yang Commodity Price Index. The World Bank Economic Review, pp. 1-13.

Pieschacón, A., 2012. The Value of Fiscal Discipline for Oil-exporting Countries. Journal of Monetary Economics 59 (3), 250-268.

Pindyck, R. S., 1978. The Optimal Exploration and Production of Non-renewable Resources. Journal of Political Economy 86 (5), pp. 841-861.

Ravenna, F., 2007. Vector Autoregressions and Reduced Form Representations of DSGE Models. Journal of Monetary Economics 54 (7), pp. 2048-2064.

Rees, D., Gómez-González, P., August 2013. Stochastic Terms of Trade Volatility in Small Open Economies. Research Discussion Paper 2013-10, Reserve Bank of Australia.

Rees, D., Smith, P., Hall, J., May 2015. A Multi-sector Model of the Australian Economy. Research Discussion Paper 2015-07, Reserve Bank of Australia.

Rotemberg, J. J., Woodford, M., 1996. Imperfect Competition and the Effects of Energy Price Increases on Economic Activity. Journal of Money, Credit and Banking $28(4), 549-577$.

Sachs, J. D., Warner, A. M., 2001. The Curse of Natural Resources. European Economic Review 45 (4-6), pp. 827-838, 15th Annual Congress of the European Economic Association.

Sanford J. Grossman, O. D. H., 1979. A Theory of Competitive Equilibrium in Stock Market Economies. Econometrica 47 (2), pp. 293-329.

Sims, C. A., June 1992. Interpreting the Macroeconomic Time Series Facts: The Effects of Monetary Policy. European Economic Review 36 (5), pp. 975-1000.

Stijns, JP, May 2003. An Empirical Test of the Dutch Disease Hypothesis using a Gravity Model of Trade. Mimeo, University of California at Berkeley.

Sweeney, J. L., 1993. Chapter 17 - Economic Theory of Depletable Resources: An Introduction. In: Kneese, A. V., Sweeney, J. L. (Eds.), Handbook of Natural Resource and Energy Economics. Vol. 3. Elsevier, pp. 759-854. 
Topp, V., Soames, L., Parham, D., Bloch, H., 2008. Productivity in the Mining Industry: Measurement and Interpretation. Staff Working Paper 807, Productivity Commission.

van der Ploeg, F., 2011. Natural resources: Curse or blessing? Journal of Economic Literature 49 (2), pp. 366-420.

van der Ploeg, F., Withagen, C., 2012. Too Much Coal, Too Little Oil. Journal of Public Economics 96 (12), 62-77.

Wills, S., 2013. Optimal Monetary Responses to Oil Discoveries. Economics Series Working Papers OxCarre Research Paper 121, University of Oxford, Department of Economics.

Yücel, M. K., 1989. Severance Taxes and Market Structure in an Exhaustible Resource Industry. Journal of Environmental Economics and Management 16 (2), pp. 13448. 


\section{ONLINE APPENDIX (NOT FOR PUBLICATION)}

\section{Appendix A. Data Sources}

\section{Australia}

\section{Commodity Prices}

Commodity prices are an export-weighted geometric mean of iron ore, coal, gold and average base metal prices. ${ }^{60}$ All prices are measured in real terms (deflated by the US GDP deflator) and are sourced from Australian Bureau of Agricultural and Resource Economics and Sciences (ABARES), Bloomberg, Global Financial Data, the IMF, Pfaffenzeller et al. (2007), Reserve Bank of Australia (RBA) and the United States Geological Survey (USGS). The export weights used are the 1976-2011 sample averages and are derived from the commodity export shares compiled by Gillitzer and Kearns (2005). ${ }^{61}$

\section{Reserves}

Reserves are an equally-weighted geometric mean of reserves for iron ore, coal, gold and five base metals (aluminium, zinc, copper, lead and nickel). ${ }^{62}$ These data are from Geosciences Australia (GA). Australian Bureau of Statistics (ABS) data are used to construct the 2011 estimate. ${ }^{63}$ When calculating the average rate of extraction, we use an equally weighted arithmetic average of the extraction rates calculated when using economically demonstrated reserves, and when calculated using total reserves. ${ }^{64}$ Total reserves include economically demonstrated, sub- and para-marginal reserves.

\footnotetext{
${ }^{60}$ Average base metal prices reflect an equally weighted geometric mean of aluminium, zinc, copper, lead and nickel prices.

${ }^{61}$ When making the more restrictive assumption that Australian commodity prices are an independent AR(1) process (see Appendix E), we use the longest available time series covering 1904-2011.

${ }^{62}$ Using an export-weighted average, based on the same export shares as used for the prices data, led to similar results.

${ }^{63}$ Prior to 1992 data, all measures are based on economically demonstrated reserves only. From 1992 onwards, the measures include economically demonstrated, sub- and para-marginal reserves.

${ }^{64}$ This yields the 2.04 per cent average extraction rate to which we calibrate the resource sector.
} 


\section{Non-mining Production}

Non-mining production is from the ABS and RBA. We use non-farm GDP in chain volume terms, ABS Catalogue No 5206.0, Table 41, less an estimate of mining GDP. The latter is derived from chain volume estimates of mining investment (ABS Catalogue No 5204.0, Table 64) and resource exports (ABS Catalogue No 5302.0, Table 11).

\section{Mining Investment}

Data are from the ABS Catalogue No 5204.0, Table 64, gross fixed capital formation by industry, by asset. Mining investment is the sum of investment in non-dwelling construction and machinery \& equipment.

\section{Real Exchange Rate}

The real exchange rate used is the real trade-weighted index compiled by the RBA, Statistical Table F15 Real Exchange Rates Measures.

\section{Inflation}

We use a measure of long-term inflation compiled by the RBA. It comprises the CPI excluding interest and health policy changes prior to 1993:III, Treasury underlying inflation between 1993:III and 1998:III, and the headline CPI excluding interest and tax post 1998:III.

\section{Cointegrating Relationship between World Demand and Reserves}

The cointegration estimates for world demand and reserves use the log index for Australian major trading partner GDP weighted by the share of each trading partner in manufactured exports (ABS, RBA) - a proxy for world demand - and the log index of Australian resource reserves described above.

\section{Canada}

\section{Commodity Prices}

Price is an export-weighted geometric average of the Fisher commodity price indices for energy and metals and minerals (in US dollars). Data are from Statistics Canada, CANSIM Table 176-0075. The export weights used are the average export shares of energy products and metal ores and non-metallic minerals on a customs basis, seasonally adjusted, from Feb-1988 to Jun-2013 (CANSIM Table 228-0059). 
Reserves

Reserves are an export-weighted geometric average oil, oil sands, natural gas, natural gas liquids, iron ore, copper, nickel, uranium, potash, bituminous coal and gold. Stocks are from CANSIM Tables $153-0012$ to $153-0028 .^{65}$

\section{Non-mining Production}

Non-mining production data are constructed over the period 1976 to $2000 \mathrm{using}$ GDP at factor cost in 1992, constant prices, seasonally adjusted, by Standard Industrial Classification. We subtract mining, quarrying and oil well industrial production from all industry production (Statistics Canada, CANSIM Table 379-0006). For data post-2001, we use CANSIM Table 379-0027, GDP at basic prices, seasonally adjusted, chained 2000 dollars, by North American Industry Classification System and again subtract mining, oil and gas extraction from all industry production.

\section{Mining Investment}

Mining Investment data are from CANSIM Table 031-0003, Flows and stocks of fixed non-residential capital by sector of North American Industry Classification System and asset, at 2007 constant prices. To compute total investment excluding exploration we subtract mining, oil and gas exploration investment from total mining investment.

\section{Real Exchange Rate}

We use the Bank of International Settlements (BIS) real effective exchange rate using a narrow basket (27 economies).

\section{Inflation}

Annual inflation in the Consumer Price Index of All Items in Canada sourced from the OECD and FRED (Federal Reserve Bank of St. Louis).

\footnotetext{
${ }^{65}$ Average export shares by commodity are from CANSIM Table 228-0059.
} 


\section{Norway}

\section{Commodity Prices}

Commodity prices are measured using the West Texas Intermediate Oil Price (\$US per barrel) deflated by the US GDP deflator. We use oil prices as oil and gas extraction make up a bit less than half of Norway's exports (1970 to 2011) whereas other mining constitute less than 1 per cent of exports.

\section{Reserves}

Reserves are an equally weighted geometric average of proven oil and gas reserves. Proven reserves data for both commodities are from the United States Energy Information Administration.

\section{Non-mining Production}

Non-mining production is constructed using total industry value added (at basic prices) less the sum of value added in mining and quarrying and oil and gas extraction. All data are measured at constant 2005 prices and are from Statistics Norway, Table: 09170: Production account and income generation, by industry.

\section{Mining Investment}

We use the sum of gross fixed capital formation in oil and gas extraction and transport via pipelines measured in constant 2005 prices. Data are from Statistics Norway, Table: 09181: Gross fixed capital formation and capital stocks, by type and industry.

\section{Real Exchange Rate}

We use the real effective exchange rate using a narrow basket (27 economies) (BIS).

Inflation

Annual inflation in the Norway Consumer Price Index sourced from the World Bank and FRED. 


\section{Appendix B. Restrictions on Productivity and World Demand}

Assumption (i): The logs of resource sector and non-resource sector technology are identically cointegrated with the log of the stock of domestic natural reserves:

$$
\begin{aligned}
\ln \frac{A_{t}^{r}}{R_{t} / R} & =\vartheta \ln \frac{A_{t-1}^{r}}{R_{t-1} / R}-\widetilde{\vartheta} \Delta \ln R_{t} \\
A_{t}^{n} & =A_{t}^{r}, \text { where }|\vartheta|<1
\end{aligned}
$$

Assumption (i) implies that the discovery of new reserves does not alter relative technical efficiency in the resource sector in the long run - that is, new discoveries do not result in a permanent technical bias that favours the use of reserves over labour and capital in production. It also implies that there is no long-run difference in technical efficiency between resource and non-resource producers. Evidence of spillovers from mining technology to non-mining technology is discussed in Bjørnland and Thorsrud (2016).

Assumption (ii): The log of foreign demand and the log of the stock of domestic natural reserves are cointegrated:

$$
\ln \frac{Y_{t}^{*}}{R_{t}}=\vartheta \ln \frac{Y_{t-1}^{*}}{R_{t-1}}-\widetilde{\vartheta} \Delta \ln R_{t}
$$

Cointegration of reserves and world demand for non-resource, when coupled with Assumption (i), delivers a balanced growth path. ${ }^{6}$ However, absent a complete model for the world economy, it is not clear what restrictions on demand or supply are be required to generate such a property endogenously from the model. For this reason, we appeal to empirical evidence to calibrate this relationship, as discussed below. Given Assumptions (i) and (ii), Appendix D charaterises the full detrended stationary equilibria for the endogenous and exogenous reserve economies.

\footnotetext{
${ }^{66}$ The existence of a stationary share of resource sector activity in the long-run is empirically plausible for many SCE's such as Australia and Canada. One needs both assumptions as we have three potential sector specific trends in resources, non-traded goods and non-resource exports; two cointegrating relationships are sufficient to eliminate these trends.
} 


\section{Appendix C. The IO Structure of the Models}

This section highlights the input-output (IO) structure of the models in relation to IO data for Australia. For the models that share the same IO structure, we compute Gross Value Added (GVA) shares using a final production approach, which measures the value added each sector contributes to each other sectors' value added. For the Australian data, we use the approach outlined in Bishop and Rayner (2013) and use IO tables to compute the contribution of each sector's value-added to other sectors a GVA requirements matrix.

Table C.1 reports the results and highlights that models broadly capture the IO structure of the Australian economy. Non-traded goods largely consume their own production, and do not drawn on activity from either the resource, exporting or importing sectors. Activity in the mining sector is mostly driven by GVA in its own sector and to a lesser extent GVA in the non-traded sector.

Where there are greater differences between the models and the data are in the non-resource exporting and importing sectors. The models imply an overly high share of non-traded activity, since separate capital and labour stocks are not modelled for exports. One approach to address this is to assume an additional labour input in the production of non-resource exports and that yields a 50-50 split between own sector production and the share of non-traded intermediates purchased. Doing so makes little difference to our final results and these results are available on request.

There is no separate modelling of the distribution sector for imports and so the models under-estimate the share of non-traded GVA in the import sector. However, it should be not be noted that there is much greater uncertainty about the estimates of this share (which seems quite high) as imports are not separately identified in the IO tables. We acknowledge this limitation, but more explicit modelling of the distribution of imports is unlikely to overturn the main results. 
Table C.1: GVA Requirements Matrix

\begin{tabular}{lcccc}
\hline $\begin{array}{l}\text { Australian data } \\
\text { (model implied) }\end{array}$ & Exports & Mining & Non-traded & Imports \\
\hline Exports & 0.46 & 0.02 & 0.02 & 0.04 \\
& $(0.16)$ & $(0.00)$ & $(0.00)$ & $(0.00)$ \\
Mining & 0.05 & 0.64 & 0.03 & 0.09 \\
& $(0.00)$ & $(0.84)$ & $(0.00)$ & $(0.00)$ \\
Non-traded & 0.45 & 0.31 & 0.92 & 0.41 \\
& $(0.84)$ & $(0.11)$ & $(1.00)$ & $(0.16)$ \\
Imports & 0.02 & 0.02 & 0.02 & 0.45 \\
& $(0.00)$ & $(0.05)$ & $(0.00)$ & $(0.84)$ \\
\hline Total & 1.00 & 1.00 & 1.00 & 1.00 \\
& $(1.00)$ & $(1.00)$ & $(1.00)$ & $(1.00)$ \\
\hline
\end{tabular}

Notes: Exports denote non-resource exports. Australian data estimates are based on the methodology in Bishop and Rayner (2013). Model-implied shares are in parentheses and are calculated using a final production (profits) approach.

\section{Appendix D. The Stationary Representation}

Definition 1. A symmetric small open economy general equilibrium with endogenous reserves, and under rational expectations, is given by sequences of quantities $\left\{C_{t}, C_{t}^{n}, C_{t}^{o}, Y_{t}^{d, n}, H_{t}^{n}, H_{t}^{r}, B_{t}^{*}, R_{t}, D_{t}, X_{t}, I_{t}, K_{t}, \Psi_{t}^{n}, \Psi_{t}^{o}, \Psi_{t}^{x}, \Psi_{t}^{r}, Y_{t}^{r, n}, C_{t}^{*}, \Phi_{t}\right\}$ and prices $\left\{P_{t}^{c}, P_{t}^{n}, P_{t}^{o}, P_{t}^{x^{*}}, W_{t}^{n}, W_{t}^{r}, S_{t}, Q_{t}^{r}, Q_{t}^{k}, \bar{P}_{t}^{n}, \bar{P}_{t}^{o}, \bar{P}_{t}^{x^{*}}, \widetilde{P}_{t}^{n}, \widetilde{P}_{t}^{o}, \widetilde{P}_{t}^{x^{*}}, V_{t}^{n}, U_{t}^{n}, V_{t}^{o}, U_{t}^{o}, V_{t}^{x}, U_{t}^{x}, i_{t}\right\}$ that solve Equations (D.1) to (D.45), taking the sequences $\left\{\chi_{t}, A_{t}^{r}, A_{t}^{n}\right\}$ as given by Equations (D.49) to (D.51), and foreign quantities and prices $\left\{\mathbf{y}_{t}^{*}\right\}$ as given by Equation (28), subject to the restrictions (D.52) and (D.53).

Definition 2. A symmetric small open economy general equilibrium with exogenous reserves, and under rational expectations, is given by sequences of quantities $\left\{C_{t}, C_{t}^{n}, C_{t}^{o}, Y_{t}^{d, n}, H_{t}^{n}, H_{t}^{r}, B_{t}^{*}, X_{t}, I_{t}, K_{t}, \Psi_{t}^{n}, \Psi_{t}^{o}, \Psi_{t}^{x}, \Psi_{t}^{r}, Y_{t}^{r, n}, C_{t}^{*}, \Phi_{t}\right\}$ and prices $\left\{P_{t}^{c}, P_{t}^{n}, P_{t}^{o}, P_{t}^{x^{*}}, W_{t}^{n}, W_{t}^{r}, S_{t}, Q_{t}^{r}, Q_{t}^{k}, \bar{P}_{t}^{n}, \bar{P}_{t}^{o}, \bar{P}_{t}^{x^{*}}, \widetilde{P}_{t}^{n}, \widetilde{P}_{t}^{o}, \widetilde{P}_{t}^{x^{*}}, V_{t}^{n}, U_{t}^{n}, V_{t}^{o}, U_{t}^{o}, V_{t}^{x}, U_{t}^{x}, i_{t}\right\}$ that solve Equations (D.3) to (D.45), taking the sequences $\left\{\chi_{t}, A_{t}^{r}, A_{t}^{n}\right\}$ as given by Equations (D.49) to (D.51), and foreign quantities and prices $\left\{\mathbf{y}_{t}^{*}\right\}$ as given by Equation (28), subject to the restrictions (D.52) and (D.53), and setting $D_{t}=0$ and $R_{t}=R$ for all $t$. 
The stationary detrended system is given by:

$$
\begin{aligned}
& \frac{R_{t+1}}{R_{t}}=1+\omega_{t+1} \frac{D_{t}}{R_{t}}-\frac{X_{t}}{R_{t}} \\
& \frac{\frac{\partial C\left(D_{t}, R_{t}\right)}{\partial D_{t}}}{P_{t}^{c}}=\frac{Q_{t}^{r}}{P_{t}^{c}} \\
& \frac{S_{t}}{P_{t}^{c}} P_{t}^{*}=\frac{Q_{t}^{k}}{P_{t}^{c}}\left(1-\Xi\left(\frac{I_{t} / R_{t}}{I_{t-1} / R_{t-1}} \frac{R_{t}}{R_{t-1}}\right)-\Xi^{\prime}\left(\frac{I_{t} / R_{t}}{I_{t-1} / R_{t-1}} \frac{R_{t}}{R_{t-1}}\right) \frac{I_{t} / R_{t}}{I_{t-1} / R_{t-1}} \frac{R_{t}}{R_{t-1}}\right) \\
& +\beta E_{t}\left(\widetilde{M}_{t+1 \mid t} \frac{Q_{t+1}^{k}}{P_{t+1}^{c}} \Xi^{\prime}\left(\frac{I_{t+1} / R_{t+1}}{I_{t} / R_{t}} \frac{R_{t+1}}{R_{t}}\right)\left(\frac{I_{t+1} / R_{t+1}}{I_{t} / R_{t}} \frac{R_{t+1}}{R_{t}}\right)^{2}\right) \\
& \frac{K_{t+1}}{R_{t+1}} \frac{R_{t+1}}{R_{t}}=(1-\delta) \frac{K_{t}}{R_{t}}+\left(1-\Xi\left(\frac{I_{t} / R_{t}}{I_{t-1} / R_{t-1}}\right)\right) \frac{I_{t}}{R_{t}} \\
& \frac{S_{t}}{P_{t}^{c}} P_{t}^{r^{*}}=(1+\zeta) \frac{W_{t}^{r}}{P_{t}^{c} R_{t}} \frac{R_{t}}{A_{t}^{r}}\left(\frac{X_{t}}{R_{t}}\right)^{\zeta}\left(\frac{K_{t}}{R_{t}}\right)^{-\mu}+\frac{Q_{t}^{r}}{P_{t}^{c}} \\
& \frac{Q_{t}^{r}}{P_{t}^{c}}=\beta E_{t}\left(\widetilde{M}_{t, t+1}(\zeta-\mu) \frac{W_{t+1}^{r}}{R_{t+1} P_{t+1}^{c}} \frac{R_{t+1}}{A_{t+1}^{r}}\left(\frac{X_{t+1}}{R_{t+1}}\right)^{1+\zeta}\left(\frac{K_{t+1}}{R_{t+1}}\right)^{-\mu}\right) \\
& +\beta E_{t}\left(\widetilde{M}_{t+1 \mid t} \frac{Q_{t+1}^{r}}{P_{t+1}^{c}}\right) \\
& \frac{Q_{t}^{k}}{P_{t}^{c}}=\beta E_{t}\left(\widetilde{M}_{t+1 \mid t} \mu \frac{W_{t+1}^{r}}{R_{t+1} P_{t+1}^{c}} \frac{R_{t+1}}{A_{t+1}^{r}}\left(\frac{X_{t+1}}{R_{t+1}}\right)^{1+\zeta}\left(\frac{K_{t+1}}{R_{t+1}}\right)^{-\mu-1}\right) \\
& +\beta E_{t}\left(\widetilde{M}_{t+1 \mid t} \frac{Q_{t+1}^{k}}{P_{t+1}^{c}}(1-\delta)\right) \\
& \frac{\Psi_{t}^{R}}{P_{t}^{c} R_{t}}=\frac{S_{t}}{P_{t}^{c}} P_{t}^{r^{*}} \frac{X_{t}}{R_{t}}-\frac{W_{t}^{r}}{R_{t} P_{t}^{c}} \frac{R_{t}}{A_{t}^{r}}\left(\frac{X_{t}}{R_{t}}\right)^{1+\zeta}\left(\frac{K_{t}}{R_{t}}\right)^{-\mu}-\frac{S_{t}}{P_{t}^{c}} P_{t}^{*} \frac{I_{t}}{R_{t}}-\frac{C\left(D_{t}, R_{t}\right)}{P_{t}^{c} R_{t}} \\
& \frac{X_{t}}{R_{t}}=\left(\frac{A_{t}^{r}}{R_{t}} H_{t}^{r}\right)^{\eta}\left(\frac{K_{t}}{R_{t}}\right)^{\gamma} \\
& \frac{D_{t}}{R_{t}}=\frac{Y_{t}^{r, n} / R_{t}}{\frac{Q^{r}}{\phi_{m c}}} \\
& \widetilde{\Theta}_{t}=\beta E_{t}\left(\left(1+i_{t}\right) \frac{P_{t}^{c}}{P_{t+1}^{c}} \widetilde{\Theta}_{t+1} \frac{R_{t}}{R_{t+1}}\right) \\
& \widetilde{\Theta}_{t}=\beta E_{t}\left(\left(1+i_{t}^{*}\right) \Phi_{t} \frac{P_{t}^{c}}{P_{t+1}^{c}} \widetilde{\Theta}_{t+1} \frac{S_{t+1}}{S_{t}} \frac{R_{t}}{R_{t+1}}\right) \\
& \frac{W_{t}^{r}}{R_{t} P_{t}^{c}} \widetilde{\Theta}_{t}=\varsigma \xi_{h} \frac{H_{t}^{r^{\frac{1}{\gamma_{h}}-1}}}{H^{r}}\left(\frac{H_{t}^{n^{\frac{1}{\gamma_{h}}}}}{H^{n}}+\frac{H_{t}^{r^{\frac{1}{\gamma_{h}}}}}{H^{r}}\right)
\end{aligned}
$$




$$
\begin{aligned}
& \frac{C_{t}}{R_{t}}=\frac{W_{t}^{n}}{R_{t} P_{t}^{c}} H_{t}^{n}+\frac{W_{t}^{r}}{R_{t} P_{t}^{c}} H_{t}^{r}+\frac{S_{t}}{P_{t}^{c}} \frac{B_{t-1}^{*}}{R_{t-1}} \frac{R_{t-1}}{R_{t}}+\nu \frac{\Psi_{t}^{r}}{R_{t} P_{t}^{c}} \\
& -\frac{S_{t}}{P_{t}^{c}} \frac{B_{t}^{*}}{R_{t}} \frac{1}{\left(1+i_{t}^{*}\right) \Phi_{t}}+\frac{\Psi_{t}^{n}}{R_{t} P_{t}^{c}}+\frac{\Psi_{t}^{o}}{R_{t} P_{t}^{c}}+\frac{\Psi_{t}^{x}}{R_{t} P_{t}^{c}}-\frac{T}{R_{t} P_{t}^{c}} \\
& \frac{C_{t}}{R_{t}}=\left[(1-\alpha)^{\frac{1}{\eta_{c}}}\left(\frac{C_{t}^{n}}{R_{t}}\right)^{\frac{\eta_{c}-1}{\eta_{c}}}+(\alpha)^{\frac{1}{\eta_{c}}}\left(\frac{C_{t}^{o}}{R_{t}}\right)^{\frac{\eta_{c}-1}{\eta_{c}}}\right]^{\frac{\eta_{c}}{\eta_{c}-1}} \\
& \frac{C_{t}^{n}}{R_{t}}=(1-\alpha)\left(\frac{P_{t}^{n}}{P_{t}^{c}}\right)^{-\eta_{c}} \frac{C_{t}}{R_{t}} \\
& \frac{C_{t}^{o}}{R_{t}}=\alpha\left(\frac{P_{t}^{o}}{P_{t}^{c}}\right)^{-\eta_{c}} \frac{C_{t}}{R_{t}} \\
& \frac{\bar{P}_{t}^{n}}{P_{t}^{c}}=\left(1-\tau_{n}\right)\left(\frac{\theta_{n}}{\theta_{n}-1}\right) \frac{V_{t}^{n} /\left(P_{t}^{c}\right)^{\theta_{n}}}{U_{t}^{n} /\left(P_{t}^{c}\right)^{\theta_{n}-1}} \\
& \frac{V_{t}^{n}}{\left(P_{t}^{c}\right)^{\theta_{n}}}=\frac{Y_{t}^{d, n}}{R_{t}} \widetilde{\Theta}_{t}\left(\frac{P_{t}^{n}}{P_{t}^{c}}\right)^{\theta_{n}} \frac{W_{t}^{n}}{R_{t} P_{t}^{c}} \frac{R_{t}}{A_{t}^{n}} \chi_{t}+\beta \phi_{n} E_{t}\left(\frac{V_{t+1}^{n}}{\left(P_{t+1}^{c}\right)^{\theta_{n}}}\left(\frac{P_{t+1}^{c}}{P_{t}^{c}}\right)^{\theta_{n}}\right) \\
& \frac{U_{t}^{n}}{\left(P_{t}^{c}\right)^{\theta_{n}-1}}=\frac{Y_{t}^{d, n}}{R_{t}} \widetilde{\Theta}_{t}\left(\frac{P_{t}^{n}}{P_{t}^{c}}\right)^{\theta_{n}}+\beta \phi_{n} E_{t}\left(\frac{U_{t+1}^{n}}{\left(P_{t+1}^{c}\right)^{\theta_{n}-1}}\left(\frac{P_{t+1}^{c}}{P_{t}^{c}}\right)^{\theta_{n}-1}\right) \\
& \frac{P_{t}^{n}}{P_{t}^{c}}=\left(\left(1-\phi_{n}\right)\left(\frac{\bar{P}_{t}^{n}}{P_{t}^{c}}\right)^{1-\theta_{n}}+\phi_{n}\left(\frac{P_{t-1}^{n}}{P_{t-1}^{c}} \frac{P_{t-1}^{c}}{P_{t}^{c}}\right)^{1-\theta_{n}}\right)^{\frac{1}{1-\theta_{n}}} \\
& \frac{\Psi_{t}^{n}}{R_{t} P_{t}^{c}}=\frac{P_{t}^{n}}{P_{t}^{c}} \frac{Y_{t}^{d, n}}{R_{t}}-\left(1-\tau_{n}\right) \frac{W_{t}^{n}}{R_{t} P_{t}^{c}} H_{t}^{n} \\
& \frac{\bar{P}_{t}^{o}}{P_{t}^{c}}=\left(1-\tau_{o}\right)\left(\frac{\theta_{o}}{\theta_{o}-1}\right) \frac{V_{t}^{o} /\left(P_{t}^{c}\right)^{\theta_{o}}}{U_{t}^{o} /\left(P_{t}^{c}\right)^{\theta_{o}-1}} \\
& \frac{V_{t}^{o}}{\left(P_{t}^{c}\right)^{\theta_{o}}}=\frac{C_{t}^{o}}{R_{t}} \widetilde{\Theta}_{t}\left(\frac{P_{t}^{o}}{P_{t}^{c}}\right)^{\theta_{o}} \frac{S_{t}}{P_{t}^{c}} P_{t}^{*}+\beta \phi_{o} E_{t}\left(\frac{V_{t+1}^{o}}{\left(P_{t+1}^{c}\right)^{\theta_{o}}}\left(\frac{P_{t+1}^{c}}{P_{t}^{c}}\right)^{\theta_{o}}\right) \\
& \frac{U_{t}^{o}}{\left(P_{t}^{c}\right)^{\theta_{o}-1}}=\frac{C_{t}^{o}}{R_{t}} \widetilde{\Theta}_{t}\left(\frac{P_{t}^{o}}{P_{t}^{c}}\right)^{\theta_{o}}+\beta \phi_{o} E_{t}\left(\frac{U_{t+1}^{o}}{\left(P_{t+1}^{c}\right)^{\theta_{o}-1}}\left(\frac{P_{t+1}^{c}}{P_{t}^{c}}\right)^{\theta_{o}-1}\right) \\
& \frac{P_{t}^{o}}{P_{t}^{c}}=\left(\left(1-\phi_{o}\right)\left(\frac{\bar{P}_{t}^{o}}{P_{t}^{c}}\right)^{1-\theta_{o}}+\phi_{o}\left(\frac{P_{t-1}^{o}}{P_{t-1}^{c}} \frac{P_{t-1}^{c}}{P_{t}^{c}}\right)^{1-\theta_{o}}\right)^{\frac{1}{1-\theta_{o}}} \\
& \frac{\widetilde{P}_{t}^{o}}{P_{t}^{c}}=\left(\left(1-\phi_{o}\right)\left(\frac{\bar{P}_{t}^{o}}{P_{t}^{c}}\right)^{-\theta_{o}}+\phi_{o}\left(\frac{\widetilde{P}_{t-1}^{o}}{P_{t-1}^{c}} \frac{P_{t-1}^{c}}{P_{t}^{c}}\right)^{-\theta_{o}}\right)^{-\frac{1}{\theta o}} \\
& \frac{\Psi_{t}^{o}}{R_{t} P_{t}^{c}}=\frac{P_{t}^{o}}{P_{t}^{c}} \frac{C_{t}^{o}}{R_{t}}-\left(1-\tau_{o}\right) \frac{S_{t}}{P_{t}^{c}} P_{t}^{*}\left(\frac{\widetilde{P}_{t}^{o} / P_{t}^{c}}{P_{t}^{o} / P_{t}^{c}}\right)^{-\theta_{o}} \frac{C_{t}^{o}}{R_{t}}
\end{aligned}
$$




$$
\begin{aligned}
& \bar{P}_{t}^{x^{*}}=\left(1-\tau_{x}\right)\left(\frac{\theta_{x}}{\theta_{x}-1}\right) \frac{V_{t}^{x}}{U_{t}^{x}} \\
& V_{t}^{x}=\frac{C_{t}^{*}}{R_{t}} \Theta_{t}\left(P_{t}^{x^{*}}\right)^{\theta_{x}} \frac{P_{t}^{n}}{P_{t}^{c}}+\beta \phi_{x} E_{t}\left(V_{t+1}^{x}\right) \\
& U_{t}^{x}=\frac{C_{t}^{*}}{R_{t}} \Theta_{t}\left(P_{t}^{x^{*}}\right)^{\theta_{x}} \frac{S_{t}}{P_{t}^{c}}+\beta \phi_{x} E_{t}\left(U_{t+1}^{x}\right) \\
& P_{t}^{x^{*}} \equiv\left(\left(1-\phi_{x}\right)\left(\bar{P}_{t}^{x^{*}}\right)^{1-\theta_{x}}+\phi_{x}\left(P_{t-1}^{x^{*}}\right)^{1-\theta_{x}}\right)^{\frac{1}{1-\theta x}} \\
& \widetilde{P}_{t}^{x^{*}}=\left(\left(1-\phi_{x}\right)\left(\bar{P}_{t}^{x^{*}}\right)^{-\theta_{x}}+\phi_{x}\left(\widetilde{P}_{t-1}^{x^{*}}\right)^{-\theta_{x}}\right)^{-\frac{1}{\theta x}} \\
& \frac{\Psi_{t}^{x}}{R_{t} P_{t}^{c}}=\frac{S_{t}}{P_{t}^{c}} P_{t}^{x^{*}} \frac{C_{t}^{*}}{R_{t}}-\left(1-\tau_{x}\right) \frac{P_{t}^{n}}{P_{t}^{c}}\left(\frac{\widetilde{P}_{t}^{x}}{P_{t}^{x^{*}}}\right)^{-\theta_{x}} \frac{C_{t}^{*}}{R_{t}} \\
& \frac{C_{t}^{*}}{R_{t}}=\left(\frac{P_{t}^{x^{*}}}{P_{t}^{*}}\right)^{-\theta_{*}} \frac{Y_{t}^{*}}{R_{t}} \\
& \frac{A_{t}^{n}}{R_{t}} \frac{H_{t}^{n}}{\chi_{t}}=\left(\frac{\widetilde{P}_{t}^{n} / P_{t}^{c}}{P_{t}^{n} / P_{t}^{c}}\right)^{-\theta_{n}} \frac{Y_{t}^{d, n}}{R_{t}} \\
& \frac{Y_{t}^{d, n}}{R_{t}}=\frac{C_{t}^{n}}{R_{t}}+\left(\frac{\widetilde{P}_{t}^{x}}{P_{t}^{x^{*}}}\right)^{-\theta_{x}} \frac{C_{t}^{*}}{R_{t}}+\frac{Y_{t}^{r, n}}{R_{t}}-\frac{D}{R} \frac{Q^{r}}{\phi_{m c}} \\
& \frac{\widetilde{P}_{t}^{n}}{P_{t}^{c}}=\left(\left(1-\phi_{n}\right)\left(\frac{\bar{P}_{t}^{n}}{P_{t}^{c}}\right)^{-\theta_{x}}+\phi_{n}\left(\frac{\widetilde{P}_{t-1}^{n}}{P_{t-1}^{c}} \frac{P_{t-1}^{c}}{P_{t}^{c}}\right)^{-\theta_{n}}\right)^{-\frac{1}{\theta_{n}}} \\
& \ln \Phi_{t}=-\varphi_{b}\left(\frac{S_{t}}{P_{t}^{c}} \frac{B_{t}^{*}}{R_{t}}-\frac{S}{P^{c}} \frac{B^{*}}{R}\right) \\
& \frac{W_{t}^{n}}{R_{t} P_{t}^{c}}=\left(\left(1-\phi_{w}\right)\left(\frac{\bar{W}_{t}^{n}}{R_{t} P_{t}^{c}}\right)^{1-\theta_{w}}+\phi_{w}\left(\frac{W_{t-1}^{n}}{R_{t-1} P_{t-1}^{c}} \frac{P_{t-1}^{c}}{P_{t}^{c}} \frac{R_{t-1}}{R_{t}}\right)^{1-\theta_{w}}\right)^{\frac{1}{1-\theta_{w}}} \\
& \frac{W_{t}}{R_{t} P_{t}^{c}}=\left(\frac{\varepsilon_{w}}{\varepsilon_{w}-1}\right) \frac{U_{t}^{H}}{-P_{t}^{c} V_{t}^{H} R_{t}} \\
& P_{t}^{c} V_{t}^{H} R_{t}=H_{t}^{n} \frac{\partial U\left(C_{t}, H_{t}^{n}, H_{t}^{r}\right)}{\partial C_{t}} R_{t}+\beta \theta_{w} E_{t}\left(P_{t+1} V_{t+1}^{H} R_{t+1} \frac{P_{t}^{c}}{P_{t+1}^{c}} \frac{R_{t}}{R_{t+1}}\right) \\
& U_{t}^{H}=-\varsigma \xi_{h} \gamma_{h}\left(\frac{H_{t}^{n^{\frac{1}{\gamma_{h}}}}}{H^{n}}+\frac{H_{t}^{r^{\frac{1}{\gamma_{h}}}}}{H^{r}}\right)^{\xi_{h} \gamma_{h}-1} \frac{H_{t}^{n^{\frac{1}{\gamma_{h}}}}}{H^{n}}+\beta \theta_{w} E_{t}\left(U_{t+1}^{H}\right) \\
& P_{t}^{c} V_{t}^{H} R_{t}=H_{t}^{n} \widetilde{\Theta}_{t}+\beta \theta_{w} E_{t}\left(P_{t+1} V_{t+1}^{H} R_{t+1} \frac{P_{t}^{c}}{P_{t+1}^{c}} \frac{R_{t}}{R_{t+1}}\right)
\end{aligned}
$$


and where monetary policy is given by:

$$
\ln \left(1+i_{t}\right)=\left(1-\rho_{i}\right) \ln (1+\bar{i})+\left(1-\rho_{i}\right) \rho_{\pi} \ln \left(\frac{P_{t+1}^{c}}{P_{t}^{c}}\right)+\rho_{i} \ln \left(1+i_{t-1}\right)
$$

and we have defined:

$$
\begin{aligned}
\widetilde{\Theta}_{t} & \equiv \frac{R_{t}}{C_{t}}\left(\frac{C_{t} / R_{t}}{C_{t-1} / R_{t-1}} \frac{R_{t}}{R_{t-1}}\right)^{1-\xi_{c}} \\
C\left(D_{t}, \widetilde{R}_{t}\right) & \equiv P_{t}^{n} \frac{Q^{r}}{\phi_{m c}}\left(e^{\phi_{m c}\left(\frac{D_{t}}{\bar{R}_{t}}-\frac{D}{\widetilde{R}}\right)} \widetilde{R}_{t}-\widetilde{R}\right) \\
\widetilde{M}_{t+1 \mid t} & \equiv\left(\nu \frac{\widetilde{\Theta}_{t+1}}{\widetilde{\Theta}_{t}} \frac{R_{t}}{R_{t+1}}+1-\nu\right)
\end{aligned}
$$

given the processes:

$$
\begin{aligned}
\ln \chi_{t} & =\rho_{r} \ln \chi_{t-1}+\Upsilon \varepsilon_{t}^{r^{*}} \\
\ln \frac{A_{t}^{r}}{R_{t} / R} & =\vartheta \ln \frac{A_{t-1}^{r}}{R_{t-1} / R}-\widetilde{\vartheta} \Delta \ln R_{t} \\
A_{t}^{n} & =A_{t}^{r}
\end{aligned}
$$

and subject to the restrictions:

$$
\begin{aligned}
\ln P_{t}^{r^{*}} & =\rho_{r} \ln P_{t-1}^{r^{*}}+\varepsilon_{t}^{r^{*}} \\
\ln \frac{Y_{t}^{*} / Y^{*}}{R_{t} / R} & =\vartheta \ln \frac{Y_{t-1}^{*} / Y^{*}}{R_{t-1} / R}-\widetilde{\vartheta} \Delta \ln R_{t}
\end{aligned}
$$




\section{Appendix E. Robustness}

Can a VAR Recover the Structural IRFs to a Resource Price Shock?

As discussed in Section 4.2, subsets of the models parameters are estimated using a GMM procedure that matches the IRFs obtained from each theoretical model with those of an empirical VAR. An important question is whether the empirical VAR can recover the model-theoretic IRFs? ${ }^{67}$ To address this, we simulate 1000 draws from the endogenous and exogenous reserves and then estimate a VAR on each simulated data set, using the same specification as that used for the empirical VAR. We then compare the difference between the model-theoretic IRFs, and those of the VARs estimated on simulated data. ${ }^{68}$

Figures E.1 and E.2 report the results. The relatively small discrepancy between the model-theoretic IRFs and those from the empirical VARs on simulated data, confirm that the latter provide a good approximation of the model-implied effects of shocks to commodity prices, at least asymptotically. This suggests that our identification strategy is locally valid around the benchmark parameterisation used in the simulation for each model. Importantly, it is the deflation of domestic production and mining capital expenditure by reserves that allows the empirical VAR to recover the model-theoretic structural shocks. Without information on reserves, a standard VAR in commodity prices, output, investment, the real exchange and inflation is misspecified.

\section{Imposing Additional Restrictions on the VAR}

A second identification question relates to the assumption that resource prices are contemporaneously uncorrelated with domestic variables in the empirical VAR, but are assumed to be a statistically independent $\mathrm{AR}(1)$ process in the theoretical model. ${ }^{69}$ To check whether this difference is important, we also estimate the empirical VAR assuming the same independent $\mathrm{AR}(1)$ structure for commodity prices in both

${ }^{67}$ There has been debate on this issue (Christiano et al., 2007; Chari et al., 2008).

${ }^{68}$ This is analogous to numerically verifying the conditions outline in Ravenna (2007).

${ }^{69}$ Specifically, the empirical VAR discussed in Section $4.2\left(\mathbf{A}_{0} \mathbf{z}_{t}=\Gamma \mathbf{z}_{t-1}+\mathbf{e}_{t}\right)$ only assumes that $\mathbf{A}_{0}$ has ones along its mains diagonal and zeros on the off diagonal elements for the first row (recall that $\mathbf{z}_{t}$ is the vector of commodity prices, the real exchange rate, the ratio of domestic production to reserves, the ratio of mining investment to reserves and inflation in that order). The theoretical model additionally assumes that the off diagonal elements of the first row of $\Gamma$ are also zero. 
Figure E.1: A One per cent Innovation in Commodity Prices Empirical, Endogenous Model and Simulated-VAR IRFs
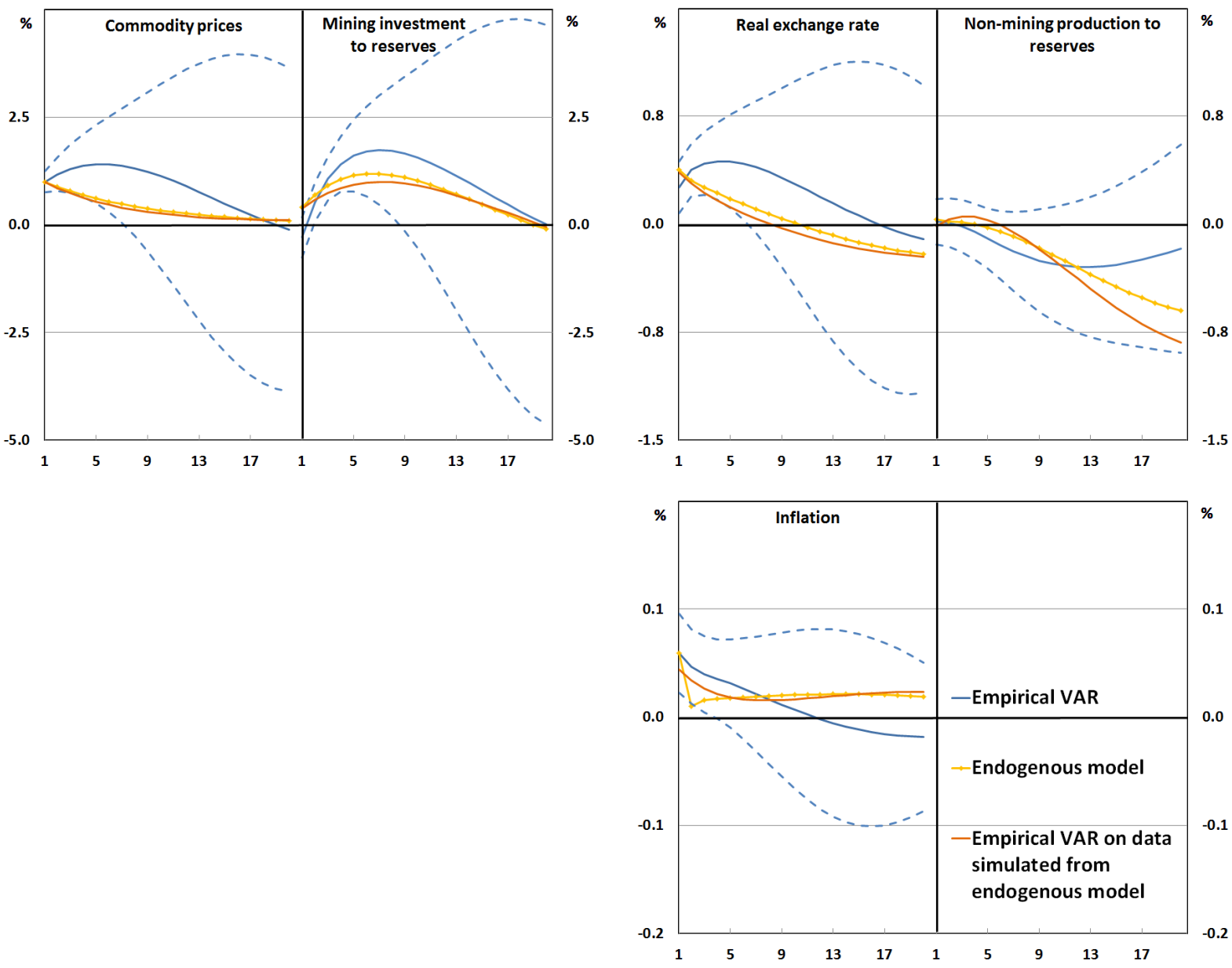

the empirical and the theoretical models. ${ }^{70}$ Comparing the empirical IRFs with and without the additional restrictions (Figure E.3), the IRFs in response to a commodity price shock are similar and the endogenous reserves model continues to provide a good fit of the empirical data in this case (without re-estimating the model).

\section{Comparing Results Across Countries}

Finally, we now consider whether our findings are robust across countries. To check this, we re-estimate the empirical VAR using Canadian and then Norwegian data. $^{71}$ In general, the IRFs are comparable with qualitatively similar responses to

\footnotetext{
${ }^{70}$ We estimate an $\mathrm{AR}(1)$ for commodity prices on annual data from 1900 to 2011 (making use of all available information on commodity prices), and then estimate the remaining equations of the VAR using limited information methods on the sample from 1976 to 2011, for which data on annual reserves are available.

${ }^{71}$ For a complete description of the data used, see Appendix A.
} 
Figure E.2: A One per cent Innovation in Commodity Prices Empirical, Exogenous Model and Simulated-VAR IRFs
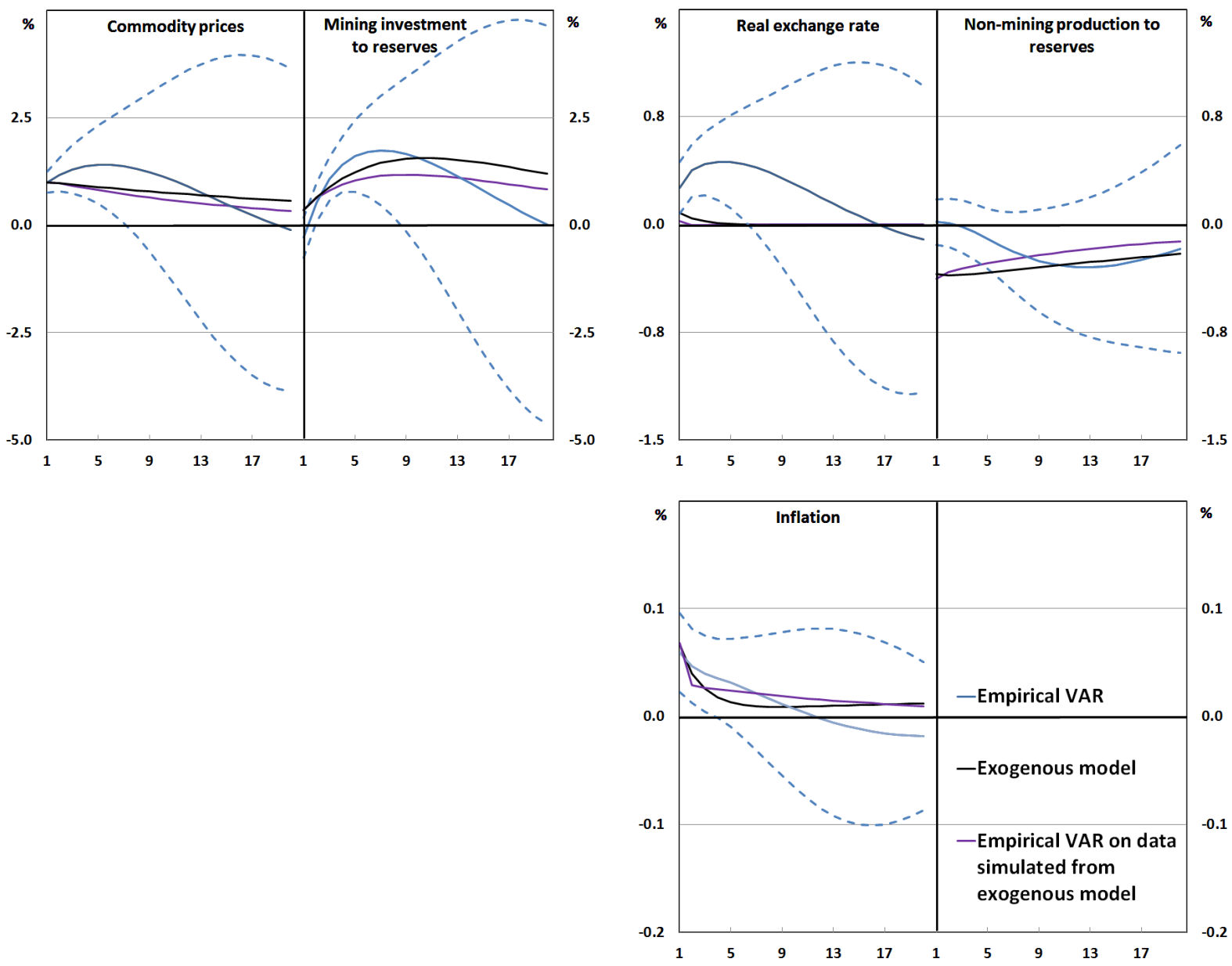

an to an exogenous one per cent increase in commodity prices (Figure E.4). Perhaps the most notable exception is the positive output response for Norway, which likely reflects additional technological spillovers from the resource to non-resource sector as emphasised by Bjørnland and Thorsrud (2016). 
Figure E.3: A One per cent Innovation in Commodity Prices - Baseline VAR and a VAR with Additional Restrictions on $\Gamma$
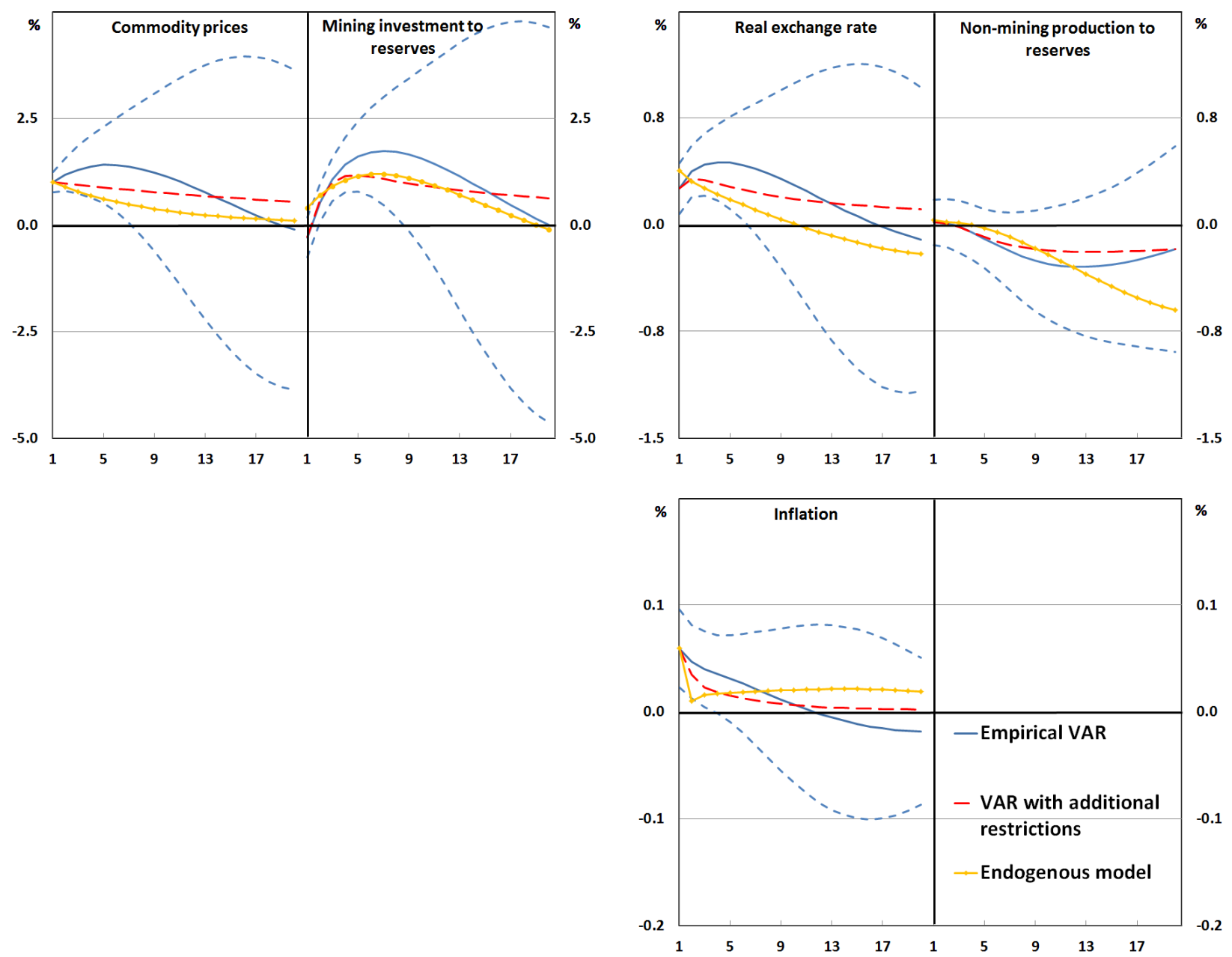

Notes: IRFs are in response to a one per cent increase in commodity prices. Estimates are from the baseline empirical VAR and a second empirical VAR that additionally imposes the restrictions that commodity prices are an exogenous $A R(1)$ process (within the VAR). 
Figure E.4: VAR Comparison Across Countries
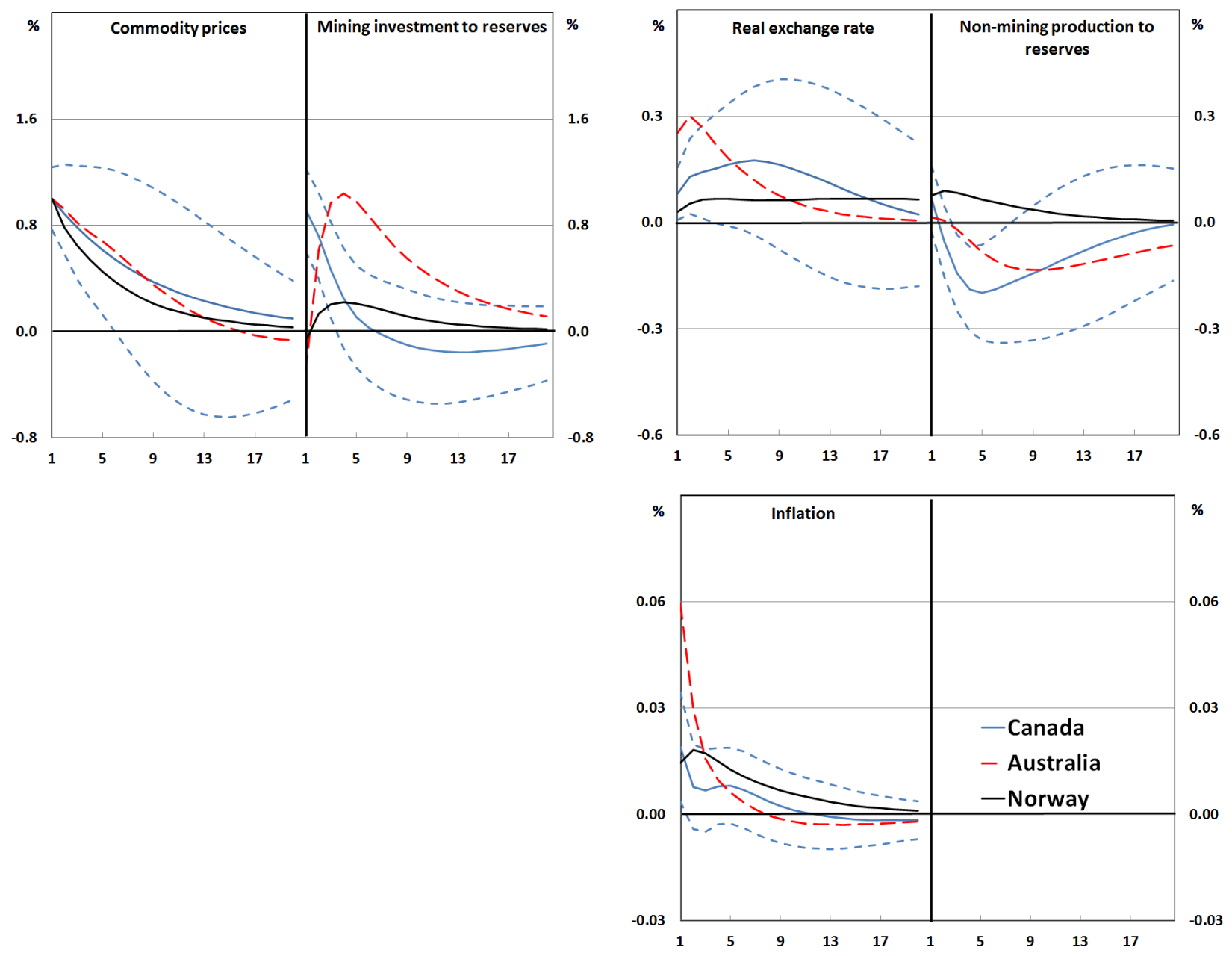

Notes: IRFs are in response to a one per cent increase in commodity prices. Estimates are constructed using a VAR on data for each country separately. The identifying assumption using Australian data is that commodity prices are an independent AR(1) process. For Canada and Norway, we assume that commodity prices are contemporaneously uncorrelated with domestic economic variables. 